\title{
Fine-scale movement, activity patterns and home-ranges of European lobster Homarus gammarus
}

\author{
Daniel J. Skerritt ${ }^{1, *}$, Peter A. Robertson ${ }^{2,3}$, Aileen C. Mill ${ }^{3}$, Nicholas V. C. Polunin ${ }^{1}$, \\ Clare Fitzsimmons ${ }^{1}$
}

\author{
${ }^{1}$ School of Marine Science and Technology, Newcastle University, Newcastle upon Tyne, NE1 7RU, UK \\ ${ }^{2}$ Animal and Plant Health Agency, Sand Hutton, York, YO41 ILZ, UK \\ ${ }^{3}$ School of Biology, Newcastle University, Newcastle upon Tyne, NE1 7RU, UK
}

\begin{abstract}
Understanding an animal's movement, distribution and activity pattern is vital for effective delivery of evidence-based management; however, such data are sparse for many economically important fishery targets, particularly the European lobster Homarus gammarus. This study aimed to elucidate high-resolution movement and activity patterns of a large cohort $(\mathrm{n}=44$; carapace length $=65-98 \mathrm{~mm}$ ) of adult European lobsters, using a passive fine-scale acoustic telemetry VEMCO Positioning System (VPS) off Northumberland (UK). This is the first application of VPS on this species and the first offshore VPS study within the UK, providing novel positional data generated via triangulation based on time difference of arrival of acoustic signals. Individual home-ranges using kernel density and minimum convex polygons showed seasonal variation: $95 \%$ utilisation distribution ranged from 244 to $7722 \mathrm{~m}^{2}$ during spring (mean \pm SE: $11104 \pm$ $397 \mathrm{~m}^{2}$ ), and declined to $237-784 \mathrm{~m}^{2}$ during autumn (mean \pm SE: $455 \pm 66 \mathrm{~m}_{\text {s.e. }}^{2}$. The study also provides evidence of behavioural differences between sexes, with males using more space than females. Daily cumulative step-length and daily minimum convex polygons highlighted that while space-use decreased during the autumn, daily distance moved increased for the majority of lobsters observed, coupled with longer durations of diel activity during autumn. These results suggest that using home-range analyses alone to describe lobster movement may inadequately represent its full behaviour. This study demonstrates the potential for passive acoustic telemetry tracking of otherwise cryptic and difficult to study marine benthic animals.
\end{abstract}

KEY WORDS: Homarus gammarus $\cdot$ Behaviour $\cdot$ Diel-cycle $\cdot$ Acoustic telemetry $\cdot$ Tracking

\section{INTRODUCTION}

Most fisheries management decisions require some understanding of the behaviour, distribution and population dynamics of the focal species. Traditionally this has been inferred via spatial differences in landings, fishing effort and fishery-independent surveys of abundance and size structure. These provide a snapshot of distribution and in some cases a useful time-series; however, numerous studies have con-

\footnotetext{
${ }^{*}$ Corresponding author: daniel.skerritt@ncl.ac.uk
}

cluded that catch per unit effort (CPUE), particularly for baited-trap fisheries, is often a poor indicator of species' distribution and abundance (Hilborn \& Walters 1992, Addison 1995, 1997, Fogarty \& Addison 1997). It is widely accepted that habitat and movement are key determinants of animal distribution, and therefore local abundances (Kahler et al. 2001, Geraldi et al. 2009), particularly for animals closely associated with the benthos. Therefore, having an understanding of localised behaviour, habitat-inter-

() The authors 2015. Open Access under Creative Commons by Attribution Licence. Use, distribution and reproduction are unrestricted. Authors and original publication must be credited. 
action and activity patterns, will aid fisheries scientists and management decisions, e.g. effective design of marine protected areas (Moland et al. 2011a, Di Lorenzo et al. 2014).

Distribution and composition of crustacean communities at a local scale are thought to be largely explained by environmental variables (Townsend et al. 2003), such as the presence of suitable shelterproviding substrate (Howard 1980) or availability of preferred prey species. Many environmental variables are dynamic or difficult to map on the scale at which most managerial decisions are implemented. Therefore, the broad physical substrate is often the most accessible and easily quantified predictor for benthic species distribution (Pittman et al. 2007). Acoustic ground discrimination techniques now allow large areas to be accurately mapped and prove useful for estimating crustacean species distributions, provided there is existing knowledge of predictable behaviour (Wiley et al. 2003, Holmes et al. 2008, Galparsoro et al. 2009, Chang et al. 2010). An animal's home-range, the area to which an animal's normal activity is confined, can be used to link their distribution and movement to the distribution of resources such as shelter or food (Börger et al. 2008) and is typically used to describe behaviour, but has limitations.

Movement and home-range data for most marine species are limited. This is particularly true for the European lobster Homarus gammarus (Smith et al. 2001), despite it being one of the most valuable commercial species in the UK (Marine Management Organisation 2013). Lobsters are considered nocturnal (Smith et al. 1998) and cannot physically regulate their body temperature; therefore, warmer temperatures and periods of darkness are thought to produce greatest movements. Previous analyses using capture-mark-recapture (CMR), with the primary goal of estimating mortality or growth rates of $H$. gammarus, have provided limited movement data that suggest $H$. gammarus has restricted movements; $<3 \mathrm{~km}$ for periods of up to a year (Jensen et al. 1994, Smith et al. 2001, Jørstad et al. 2004, Agnalt et al. 2007). H. gammarus are generally believed to make short random movements away from shelter, which could be prompted by local competition for food, shelter and mates (Pawson 1995). Only a small number of individuals have been observed to travel up to $15 \mathrm{~km}$ in a season (Thomas 1954, Simpson 1961). Furthermore, movements and distributions are largely influenced by the spatial distribution of hard substrates, interpreted by positions of capture and recaptures, and often reflected in the distribution of commercial fish- ing effort (Smith et al. 2001). However, CMR studies are impeded by low tag-returns, a lack of fine-scale resolution and only provide discrete positional data at the time of capture. Studies of colonisation by lobsters of an artificial reef in the UK, positioned $3 \mathrm{~km}$ away from suitable lobster ground, are evidence that H. gammarus can travel over soft habitat, but previous approaches have been unable to observe this behaviour directly.

Studies addressing the spatial behaviour of the American lobster H. americanus (Bowlby et al. 2007, Geraldi et al. 2009, Scopel et al. 2009) have revealed habitat effects on movement and the presence of transient and resident portions of the population. However, findings should not be extrapolated to another species (Mercer et al. 2001), especially considering the reported differences between the 2 Homarus species (Phillips 2013). Recent advances in acoustic telemetry (AT) tracking techniques offer an innovative means of near continuous in situ observation, with minimal disturbance to the animal. These technologies have begun to produce novel insights into clawed lobster behaviour (MacArthur et al. 2008, Watson et al. 2009, Moland et al. 2011a, McMahan et al. 2013a). AT reduces the reliance upon baitedtraps, which are constrained by issues of variable effort, catchability and trap saturation; these issues have historically hindered the robustness of findings. Despite the obvious advantages, AT has not yet been applied to crustaceans in the UK (Guerra-Castro et al. 2011), where movement and space-utilisation remain poorly investigated (but see Smith et al. 1998, 2001). AT and data storage tags have been applied to H. gammarus on 3 occasions in Norway (van der Meeren 1997, Moland et al. 2011a, Wiig et al. 2013). However, the fishery, biological parameters and environmental conditions are quite different between the UK and Norway.

Previous studies highlight the potential of this technology; Smith et al. (2000) used electromagnetic telemetry to monitor the presence of $H$. gammarus at an artificial reef and verified the nocturnal nature of $H$. gammarus and Cancer pagurus, but could not describe movement or space-use (Smith et al. 2000). Van der Meeren (1997) pioneered the use of AT to study European crustaceans, using a VRAP positioning system (Vemco) to detect behavioural differences of transplanted and native lobsters. However, limitations of VRAP and the small sample size $(n=4)$ restricted the conclusions of the study. Two recent studies in Norway (Moland et al. 2011a, Wiig et al. 2013) utilised AT to elucidate long-term home-ranges of lobsters; these studies 
provide valuable data but were unable to provide detail of habitat-utilisation or movement.

Here, we explored short-term movements and space-utilisation of freely moving $H$. gammarus in their natural habitat using a VEMCO Positioning System (VPS). VPS provides credible fine-scale positional data with individual error estimates, via hyperbolic triangulation. The primary objectives were to quantify individual homeranges, movement characteristics and seasonal and diel activity patterns, and relate these to substrate, sex and size of the lobsters. There were 3 hypotheses addressed: (1) lobster home-ranges and movements were restricted to hard substrate; (2) the greatest space-utilisation and distances travelled were displayed by large, male lobsters, based on previous findings suggesting males are more 'risk-taking' and the weak positive relationship between size and distance travelled (Jensen et al. 1994, Rowe 2001, Smith et al. 2001, Wiig et al. 2013); and (3) movement and space-use vary between seasons and over the diel cycle, with dark and warm periods leading to greatest movements.

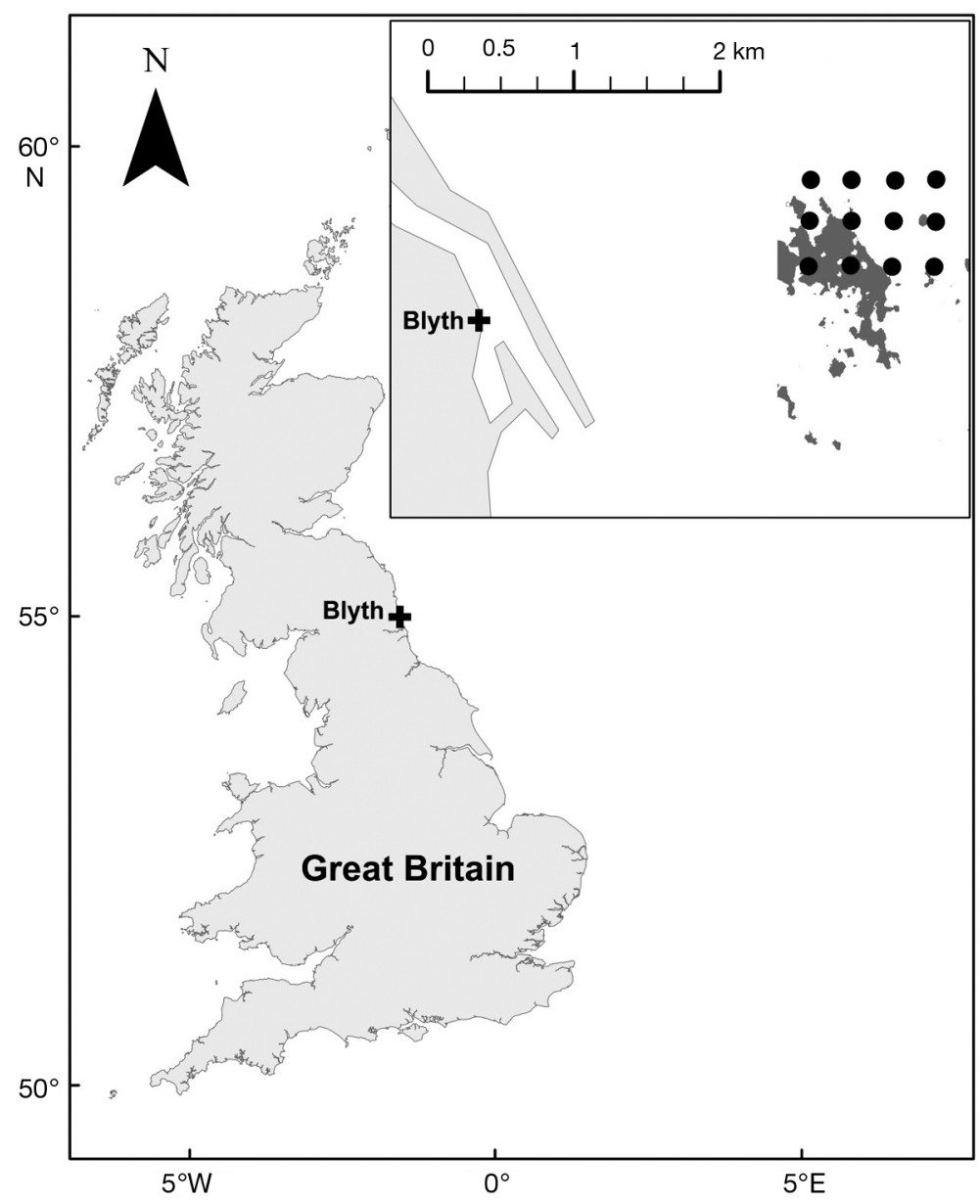

\section{MATERIALS AND METHODS}

\section{Study site}

Fig. 1. Location of the acoustic telemetry VEMCO Positioning System array, consisting of 12 VR2W acoustic receivers (-), off Blyth, Northumberland, UK. Olex data indicates the hard reef in dark grey (inset)

The study was conducted $2 \mathrm{~km}$ off Blyth, Northum-

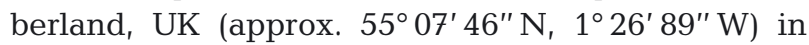
2013. Water depth ranges from $16 \mathrm{~m}$ at the south-east to $31 \mathrm{~m}$ at the west of the site. The site is composed of mixed hard and soft substrate; a large rocky-reef dominated by rock and cobble runs from the northwest to southern centre of the site and patches of coarse sand and mud occur throughout (Fig. 1). Substrate hardness data were continuously collected via the vessel's on-board Olex 8.0 software. The software measures relative change in substrate hardness by reporting backscatter values from the vessel's singlebeam echo-sounder as a ratio of sent and received acoustic energy via proprietary algorithmic treatment of the sonogram. This translates linearly into a scale from 1 (low reflection) to 100 (0 dB energy lost). However, Olex cannot assess bottom roughness and only provides a proxy for substrate hardness, precluding discrimination between habitat types
(Conner \& Plowman 2001, Elvenes et al. 2014). Olex provides broad substrate classification, has been previously verified by drop-down camera work within the region and was the best available at the time of writing.

\section{Data collection}

An AT VPS (VEMCO Division) was used to monitor lobster positions over 2 study periods in 2013: 23 April to 03 June (spring) and 17 September to 20 November (autumn). The 2 study periods were characterised by differences in day-length and daily seafloor water temperature. Spring day-length ranged from 14.70 to $17.06 \mathrm{~h}$ (local time) $\left(\bar{x}_{42}=16 \mathrm{~h}\right.$ ), and seafloor water temperature ranged from 5.60 to $8.14^{\circ} \mathrm{C}\left(\bar{x}_{42}=7.14^{\circ} \mathrm{C}\right)$; while autumn day-length ranged from 8.12 to $12.59 \mathrm{~h}\left(\bar{x}_{65}=10.27 \mathrm{~h}\right)$, and 
seafloor temperature ranged from 9.63 to $12.43^{\circ} \mathrm{C}$ $\left(\bar{x}_{65}=11.29^{\circ} \mathrm{C}\right)$.

The VPS consisted of an array of 12 VR2W single channel omni-directional acoustic receivers, moored in a grid arrangement (Fig. 1), $4 \mathrm{~m}$ above the seafloor. A V13 synchronisation tag (synctag) was moored on the seafloor beneath each receiver to allow for characterisation of variability in detection rates (Mathies et al. 2014) and for post-hoc correction of clock drift (Andrews et al. 2011). Individual surface markers were attached to a second weight, connected to receiver-weights via a $50 \mathrm{~m}$ bottom-line, ensuring receiver movement was limited. A single V13T reference tag was independently moored in the centre of the site to allow for adjustments due to movement of receivers and to record hourly seafloor temperature. V13 and V13T signals include an individual ID number; the V13T tag also emits a temperature reading. Signals are repeated after a random delay between 500 and $700 \mathrm{~s}$ for the synctags and reference tags, and 200 and $400 \mathrm{~s}$ for animal tags, minimising the probability of signal collision. The chosen delay provides high-resolution data, considering reported walking speeds of Homarus americanus (O'Grady et al. 2001).

A range-test was conducted prior to the study to determine the distance that VR2Ws accurately detect the V13 signal. As substrate complexity can interfere with detection, the range-test was conducted over 'soft-homogenous' substrate and 'hard-complex' substrate. Range-tests found that high tides produced a slight decrease in detection range. Background noise, wind and poor weather had no discernible effect despite very strong winds being recorded. Tags were considered to be well suited to the site; the soft range-test having $>80 \%$ detection rate at $300 \mathrm{~m}$ and $>50 \%$ detection rate up to $600 \mathrm{~m}$; hard rangetest had $>85 \%$ detection rate at $400 \mathrm{~m}$ and $>20 \%$ detection rate up to $600 \mathrm{~m}$. Therefore, receivers were spaced conservatively during the study, approx. $300 \mathrm{~m}$ apart, to increase area of overlapping detection and likelihood of multiple receivers detecting tag signals. The complete array covered an area of approx. $1.5 \mathrm{~km}^{2}$ (Fig. 1).

Five days prior to the setting of the VPS array (18 April 2013), 2 strings of 8 commercial parlour traps were baited and set in the centre of the site in order to catch lobsters for tracking. Lobsters were measured (carapace length, CL), sexed and fitted with a uniquely numbered Hallprint T-bar ID tag (TBA1, yellow, $50 \times 2 \mathrm{~mm}$, Hallprint Pty.), inserted in the dorsal musculature behind the carapace to permit identification of recaptured lobsters. Each lobster was also fitted with a V13 coded transmitter (6 $\mathrm{g}$ in water, ca. $1 \%$ body weight), attached by means of a cable tie and plastic tubing harness, between the denticles on the carpus of the largest claw (Moland et al. 2011a). There are no indications that tags impair lobster behaviour (Cowan et al. 2007, Moland et al. 2011a). Lobster handling time was $\leq 10$ min before being released from their capture location with as little disturbance as possible. Catching, tagging and releasing the lobster prior to the start of the study allowed individuals to become accustomed to the tag. Only positions gained $48 \mathrm{~h}$ after release were included in the analysis. Tagged lobsters ranged in size from 65 to $98 \mathrm{~mm} \mathrm{CL}\left(\bar{x}_{44}=78 \mathrm{~mm}\right)$, a size distribution similar to that of the local population. All 44 lobsters tagged (23 male and 21 female, 4 of which were ovigerous) were in inter-moult stage and had no recent signs of injury.

Positions were calculated hyperbolically by VEM$\mathrm{CO}$, based on time differences of arrival (TDOA) of acoustic signals at 3 or more receivers, calculating a single position by averaging all intermediate positions from receiver pairs (Smith 2013). Spring and autumn data stored within receivers were downloaded on 3 June 2013 and 20 November 2013, respectively.

For each animal tag calculated position, VPS provides an estimate of horizontal positioning error (HPE). HPE offers a level of confidence in the location of the estimated position, based on water temperature, salinity, the geometry of the tag and detecting receivers, and information obtained by analysing the error of VPS calculated positions for synctags of known location (Smith 2013). Positions with high HPE are likely to provide less information on the position of the animal. To relate HPE as a measurement of error sensitivity to error in absolute terms, the relationship between HPE and HPE in terms of metres (HPEm) for the stationary synctags of known location was analysed by grouping calculated synctag positions, based on ranges of HPE of bin-width 1 , and for each bin calculating the $95 \%$ quantile of HPEm. This approach was similar to the twicedistance root-mean-square approach commonly used (Misra \& Enge 2006). A strong correlation was found and the subsequent regression slope used to characterise HPEm for all animal tag positions (Scheel \& Bisson 2012, Coates et al. 2013). Mean ( \pm SE) HPEm of all synctags was $4.59 \pm 0.03 \mathrm{~m}$ during spring and $3.16 \pm 0.01 \mathrm{~m}$ during autumn.

To ensure only data gained from tags attached to living animals was analysed, rather than from shed tags emitting from the seafloor, 3 criteria must have been satisfied. (1) Animal tags displayed heteroge- 
neous hourly detection frequencies; animals produce biological patterns of hourly detections, distinct from homogenous patterns of stationary tags. (2) Animal tags showed extended periods of inactivity $(>6 \mathrm{~h}$ ) during periods of $>80 \%$ synctag detection rates; inactivity is believed to occur while lobsters are within shelter; thus, the signal is lost. (3) Animal tags displayed contranatant movement during both study periods; this was tested by visually comparing directional movement (bearing and turn angle) of synctags (caused by tidal movement and error) against animal tag movement. Movement of shed animal tags emitting from a stationary point should match that of synctags.

\section{Statistical analysis}

HPE estimates were used to filter the dataset and remove potentially erroneous animal positional fixes (HPE > 24) prior to analysis. Filtered positional data were projected into Arc GIS 10.1, which along with R 2.12.1 software, was used for all analysis. Each animal's utilisation distribution (UD) was calculated (Simpfendorfer et al. 2002, Rogers \& White 2007) using a kernel density estimator (KDE), providing a probabilistic description of an animal's space-use (Worton 1989). Individual home-ranges were defined as the smallest area containing $95 \%$ of the UD (95UD) and core home-range as the area containing $50 \%$ of the UD (50UD) (Rodgers \& Carr 2001). To ensure individual home-ranges were comparable, whilst largely avoiding over-smoothing or inflation for the majority of animals, search radius was standardised $(h=7.6 \mathrm{~m})$ (Fieberg 2007) and the cell-size of the output restricted to $0.1 \mathrm{~m}$ (Kie et al. 2010). Behavioural and methodological factors were used to guide search radius decisions (Worton 1995, Seaman \& Powell 1996). Given reported walking speeds of $H$. americanus (2.5 $\left.\mathrm{m} \mathrm{min}^{-1}\right)$ (O'Grady et al. 2001), lobsters could travel $>7.5 \mathrm{~m}$ during the V13 delay time; therefore, $h$ of $7.6 \mathrm{~m}$ is considered a biologically meaningful value. Given the high accuracy and resolution of the data, a larger search radius would calculate home-ranges that extend into area locations not identified by the data (Walter et al. 2011). This was considered more important than the fragmentation of some 95UDs, provided this study was primarily interested in quantifying areas of use and not unvisited areas or areas not essential to an animal's fitness (Walter et al. 2011). Using least-squares cross-validation to gain individual values of $h$ for each homerange is not always suitable (Silverman 1986) and leads to home-ranges being less comparable; therefore, we consider the present method to be robust. Home-ranges were also estimated by applying the minimum convex polygon (MCP) estimator (Mohr 1947); this includes all areas used by the animals within analysis and is not subject to biasing due to search radius selection or sample size.

Separate home-ranges were recorded for the spring and autumn period for lobsters that remained, allowing for direct seasonal comparisons. To test the impact of unequal durations of tracking, we further analysed home-ranges standardised by the number of days tracked. We used linear models to analyse effects of body size and sex on home-range. Olex data were used to assess substrate-use within homeranges. Shapiro-Wilks tests showed spring homerange estimates were non-normally distributed; therefore, a Kruskal-Wallis test was implemented, while home-range hardness estimates were normally distributed allowing for $t$-test analysis.

Movement path metrics, including turn angle, steplength and time interval were calculated via the Geospatial Modelling Environment (GME) platform version 0.7.2.1, using $R$ as the statistical engine. Recorded positions map continuous movement as discrete points (Turchin 1998); the shortest straight-line between consecutive positions, i.e. step-lengths, were standardised by the step time interval to create step-speed. Turning angles were defined as the angle between the bearing from $(x-1)$ to $(x)$, and the bearing from $(x)$ and $(x+1)$. Turning angle was constrained to positive values and centred on $0^{\circ}$; thus, $0^{\circ}$ shows high directionality (continuing in straight line), $180^{\circ}$ was a 'u-turn', and $90^{\circ}$ turning perpendicular to the original bearing. The sequence and distribution of step-lengths, step-speeds and turning angles provided the basis for analysis of animal movement characteristics (Turchin 1998). Analysis of movement metrics with substrate was conducted by categorising metrics by the underlying substrate hardness of position $x_{1}$ into Olex hardness categories of bin-width 1 . Due to restrictions of the study site, depth was not included in analysis. Daily space-use in terms of MCPs and daily movements in terms of cumulative step-length were compared between the lobsters present during both study periods, to understand seasonal changes in lobster movement activities.

Diel patterns of substrate-use were analysed by categorising positions as day or night, defined by day-lengths at $55^{\circ}$ latitude during the middle of the spring study period (day between 06:00 and 19:59 h, night between 20:00 and 05:59 h). Each individual position was then allocated the corresponding hard- 
ness value. Cumulative time intervals for consecutive positions, grouped by substrate hardness value within bin-width 1 , were expressed as a percentage of the total time intervals recorded across all lobsters during the spring. To highlight differences in lobster movement characteristics over substrate hardness, spring step-speed values between consecutive position were pooled for all lobsters $(\mathrm{n}=72395)$ and grouped by underlying substrate to the nearest whole integer. Step-speed was positively skewed and observed values were small and therefore converted into $\mathrm{m} \mathrm{h}^{-1}$, a constant added to each value so that the smallest value was 1 and data were $\log _{10^{-}}$ transformed. Diel patterns of activity were inferred by separately pooling detection data for synctags and animal tags into hourly bins; hourly animal tag detection frequency was displayed as a proportion of the hourly synctag detection frequency and these proportions were subsequently used as a proxy for activity (Payne et al. 2010). Receiver positions were logged consistently hour by hour; therefore, significant deviations of hourly animal detection frequency were due to behavioural effects rather than environmental or methodological factors (Lindholm et al. 2007). All synctags were well-detected across multiple receivers over both seasons, with 91.7 and $93.3 \%$ of synctag transmissions logged on 3 or more receivers, for spring and autumn, respectively.

\section{RESULTS}

During spring, $28 \%$ of possible animal tag transmissions were detected on at least 3 receivers, resulting in 72395 verified positions being calculated for 44 individual lobsters. During autumn, $24 \%$ of transmissions were detected, resulting in 32239 positions being calculated for 13 individual lobsters. Seven lobsters were excluded from spring home-range analyses as they either had tag malfunction or the tag was shed $(n=1)$, were not observed within the study area $(\mathrm{n}=3)$ or had an inadequate number of points $(<100)$ for analysis $(n=3)$. Thus, 37 individual spring home-ranges were estimated (females $=18$, males $=$ 19). Thirteen lobsters were observed during the autumn period; of these, 3 individuals either had tag malfunction or did not have adequate numbers of points for analysis $(<100)$; thus, 10 autumn homerange estimates were gained (females $=2$, males $=8$ ). Only lobsters included in home-range analysis are referred to here (Fig. 2).

Duration of tracking varied between individuals and ranged from 3 to $41 \mathrm{~d}$ in spring $\left(\bar{x}_{37}=34\right)$ and 17 to $64 \mathrm{~d}$ during autumn $\left(\bar{x}_{10}=46\right.$.) (Tables $\left.1 \& 2\right)$. No correlation was found between the duration of tracking with either size of the 50UD, 95UD, MCP, CL, sex or number of positional fixes per animal. As number of synctag fixes was not significantly different between hours, days or study periods, variation between the numbers of animal positional fixes is assumed to be a reflection of their activity or degree of site fidelity; i.e. individual behavioural variance was larger than the variance attributed to differences in sample size.

\section{Home-range analyses}

Spring 95UD ranged from 244 to $2865 \mathrm{~m}^{2}$ for females $\left(\bar{x}_{18} \pm \mathrm{SE}=1031.76 \pm 184.51 \mathrm{~m}^{2} ;\right.$ Fig. $\left.3 \mathrm{~A}\right)$ and from 384 to $7722 \mathrm{~m}^{2}$ for males $\left(\bar{x}_{19} \pm \mathrm{SE}=2,133.68 \pm\right.$ $423.47 \mathrm{~m}^{2}$; Fig. 3B). 50UD ranged from 38 to $51 \mathrm{~m}^{2}$ for females $\left(\bar{x}_{18} \pm \mathrm{SE}=154.86 \pm 25.51 \mathrm{~m}^{2}\right)$ and from 51 to $557 \mathrm{~m}^{2}$ for males $\left(\bar{x}_{19} \pm \mathrm{SE}=211.30 \pm 30.33 \mathrm{~m}^{2}\right)$. The number of separate 50UD cores in each range was not significantly different $(\mathrm{p}<0.05)$ between males $\left(\bar{x}_{19}=1.74\right)$ and females $\left(\bar{x}_{18}=1.22\right)\left(t\right.$-test ${ }_{35}: t=$ $-1.938, p=0.061)$. However, the number of separate 95UD cores was significantly different $\left(t\right.$-test $_{35}: t=$ 2.03, p < 0.05), with males $\left(\bar{x}_{19}=11.16\right)$ having a greater number than females $\left(\bar{x}_{18}=2.61\right)$ (Fig. 3 ). Male and female spring 95UD estimates were significantly different (Kruskal-Wallis ${ }_{1}: \chi^{2}=4.2696, \mathrm{p}<$ 0.05); however, 95UD-d, 50UD, 50UD-d, MCP and MCP-d spring estimates were not significantly different between sexes.

Mean substrate hardness for spring 95UD ranged from 18 to 54 for females $\left(\bar{x}_{18} \pm \mathrm{SE}=40.82 \pm 2.32\right)$ and from 20 to 52 for males $\left(\bar{x}_{19} \pm \mathrm{SE}=36.53 \pm 2.47\right)$, 50UD hardness ranged from 20 to 54 for both females and males (female: $\bar{x}_{18} \pm \mathrm{SE}=41.26 \pm 2.21_{\mathrm{SE} i}$ male: $\bar{x}_{19} \pm$ $\mathrm{SE}=36.69 \pm 2.55)($ Table 1$)$. Neither 95UD $(t$-test t4.963: : $t=1.2304, \mathrm{p}=0.2268)$ nor 50UD $\left(t\right.$-test th. $_{54}: t=1.3155$, $p=0.197$ ) home-range hardness estimates were significantly different between sexes, despite mean male hardness tending to be lower than that of females, with wider variation. A linear multiple regression model was then implemented to predict logUD50 and log95UD home-range size based on sex, size and hardness; however, neither was significant.

Autumn 95UD area ranged from 237 to $784 \mathrm{~m}^{2}$ $\left(\bar{x}_{10} \pm \mathrm{SE}=455.08 \pm 66.13 \mathrm{~m}^{2}\right)$ and 50UD area ranged from 29 to $148 \mathrm{~m}^{2}\left(\bar{x}_{10} \pm \mathrm{SE}=73.92 \pm 12.22 \mathrm{~m}^{2}\right)$ for all lobsters. Mean substrate hardness for 95UD ranged from 18 to $54\left(\bar{x}_{10} \pm \mathrm{SE}=37.67 \pm 3.70\right)$ and 50UD hardness ranged from 18 to $54\left(\bar{x}_{10} \pm \mathrm{SE}=38.31 \pm\right.$ 

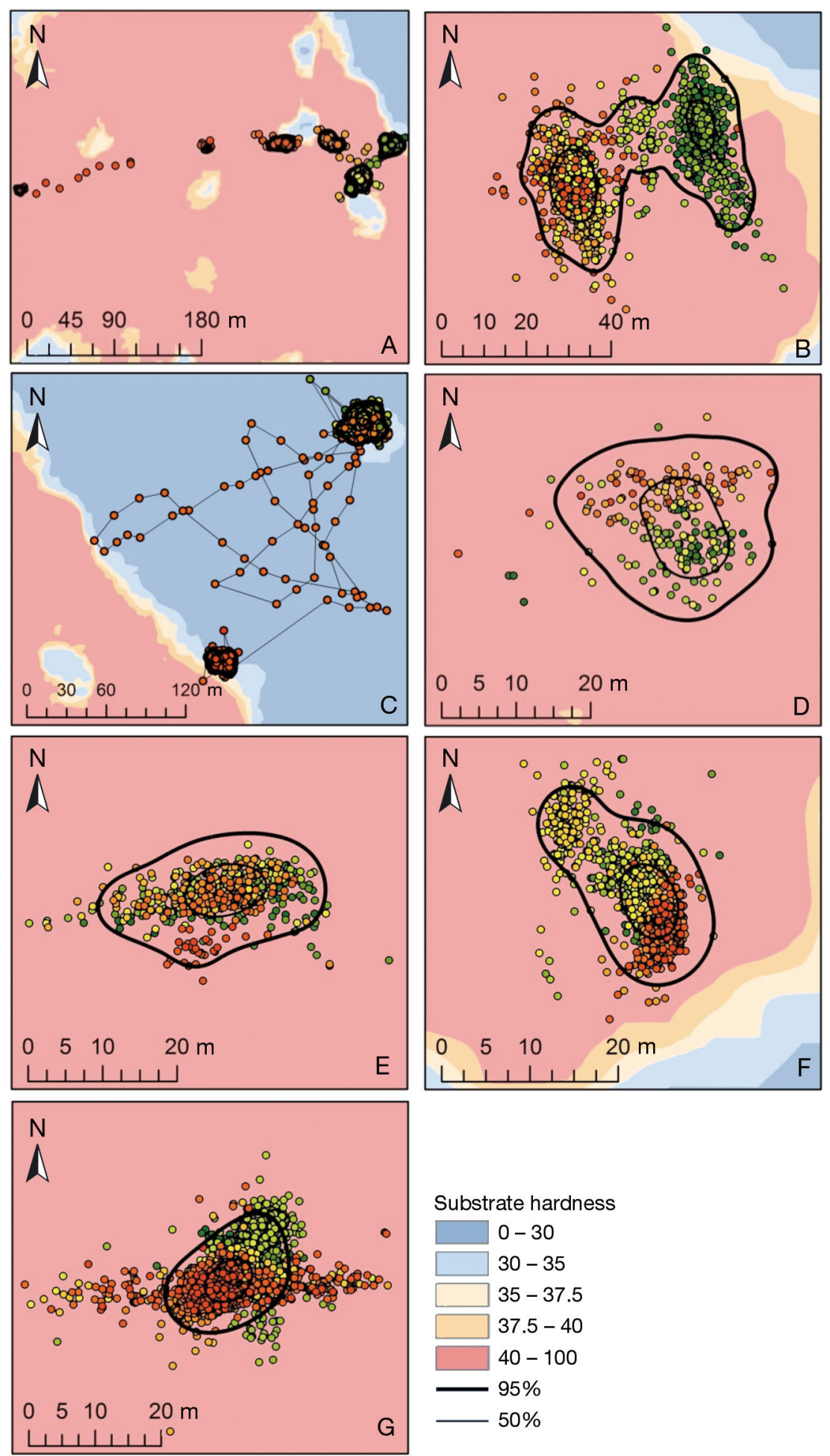

Fig. 2. Total home-ranges (95\% utilisation distribution) and core home-ranges ( $50 \%$ utilisation distribution) of selected European lobster Homarus gammarus from verified positional data during both spring and autumn 2013. Each image is of an individual's home-ranges, overlaid on Olex substrate hardness maps and all verified positions. Verified positions (dots) are coloured on a continuous scale from green (first positions) to red (last positions). Each image has its own scale: (A) lobster ID 28170, in spring (S); (B) ID $28171 \mathrm{~S}_{\text {; }}$ (C) ID $28200 \mathrm{~S}_{\text {; }}$ (D) ID $28216 \mathrm{~S}$; (E) ID 28216, in autumn (A); (F) ID $28195 \mathrm{~A}_{i}$ (G) ID $28168 \mathrm{~A}$
3.69) (Table 1). Significant differences between seasons were observed for all home-range area data (Wilcox $_{10}: W=400, \mathrm{p}<0.05$ ) (Figs. 2 $\& 4)$. However, no significant difference was observed in 50UD $(t$-test $10: t=1.7766, \mathrm{p}=0.1094)$ or 95UD hardness $\left(t\right.$-test $_{10}: t=1.8425$, $\mathrm{p}=0.09851$ ) between the 2 seasons, despite mean substrate hardness tending to be greater during autumn. However, female homerange data did not significantly differ between seasons; the difference is driven by a reduction in male home-range area, but due to the fact only 2 female lobsters remained within the site, we do not believe it is appropriate to analyse differences between sexes with such low replication. No significant differences were found between the size of an individual's CL and its substrate-use or size of its homerange area.

\section{Seasonality of movement}

Further, we compared daily mean MCP and daily mean cumulative step-lengths of all lobster present during the spring and autumn study periods (Fig. 4). Mean daily MCP was significantly lower during autumn $\left(\bar{x}_{64} \pm \mathrm{SE}=194.17 \pm 10.26\right.$ $\left.\mathrm{m}^{2}\right)$, compared with spring $\left(\bar{x}_{42} \pm \mathrm{SE}\right.$ $\left.=484.85 \pm 43.54 \mathrm{~m}^{2}\right)\left(t\right.$-test ${ }_{104}: t=$ 7.68, p < 0.01), but mean daily cumulative step-length was lower in spring $\left(\bar{x}_{42} \pm \mathrm{SE}=260.45 \pm\right.$ $\left.17.35 \mathrm{~m}^{2}\right)$ than autumn $\left(\overline{\mathrm{x}}_{64} \pm \mathrm{SE}=\right.$ $\left.347.73 \pm 16.07 \mathrm{~m}^{2}\right)(t$-test $104: t=$ -3.56, p < 0.01) (Table 3). Both the mean daily MCP and individual daily MCP for 9 of the 10 lobsters were significantly larger during the spring study period (Table 3). Daily cumulative step-length was significantly larger during spring for 4 lobsters and significantly larger during autumn for 6 lobsters (Table 3). 
Table 1. Summary of home-range statistics; number of days tracked (Days), 50 and 95\% utilisation distribution (50UD and 95UD) kernel density estimates, 50UD and 95UD standardised by number of days tracked (50UD-d and 95UD-d), the proportion of 50UD within 95UD, the mean Olex hardness value for 50UD and 95UD (50UDhard and 95UDhard), minimum convex polygon (MCP) values and MCP standardised by days tracked (MCP-d) during the spring study period. F: female; M: male

\begin{tabular}{|c|c|c|c|c|c|c|c|c|c|c|c|}
\hline ID & $\begin{array}{c}\text { CL } \\
(\mathrm{mm})\end{array}$ & Days & $\begin{array}{l}\text { 50UD } \\
\left(\mathrm{m}^{2}\right)\end{array}$ & $\begin{array}{c}\text { 50UD-d } \\
\left(\mathrm{m}^{2}\right)\end{array}$ & $\begin{array}{l}\text { 95UD } \\
\left(\mathrm{m}^{2}\right)\end{array}$ & $\begin{array}{l}\text { 95UD-d } \\
\left(\mathrm{m}^{2}\right)\end{array}$ & $\begin{array}{c}\text { 50UD:95UD } \\
(\%)\end{array}$ & $\begin{array}{l}\text { 50UD } \\
\text { hard }\end{array}$ & $\begin{array}{l}\text { 95UD } \\
\text { hard }\end{array}$ & $\begin{array}{c}\mathrm{MCP} \\
\left(\mathrm{m}^{2}\right)\end{array}$ & $\begin{array}{c}\text { MCP-d } \\
\left(\mathrm{m}^{2}\right)\end{array}$ \\
\hline \multicolumn{12}{|l|}{ Females } \\
\hline 28174 & 65 & 39 & 501.21 & 12.85 & 2864.76 & 73.46 & 17.50 & 36.38 & 31.12 & 8449.30 & 216.65 \\
\hline 28175 & 65 & 39 & 290.49 & 7.45 & 2088.18 & 53.54 & 13.91 & 53.66 & 43.14 & 12175.31 & 312.19 \\
\hline 28199 & 71 & 40 & 197.05 & 4.93 & 1255.76 & 31.39 & 15.69 & 50.23 & 52.29 & 4751.29 & 118.78 \\
\hline 28169 & 73 & 25 & 86.28 & 3.45 & 364.94 & 14.60 & 23.64 & 20.21 & 17.53 & 1423.70 & 56.95 \\
\hline 28164 & 74 & 41 & 131.46 & 3.21 & 573.71 & 13.99 & 22.91 & 41.58 & 42.91 & 1133.45 & 27.65 \\
\hline 28176 & 74 & 36 & 256.09 & 7.11 & 1253.12 & 34.81 & 20.44 & 36.69 & 36.70 & 9320.15 & 258.89 \\
\hline 28171 & 76 & 37 & 205.88 & 5.56 & 1484.80 & 40.13 & 13.87 & 50.27 & 49.44 & 3378.69 & 91.32 \\
\hline 28172 & 76 & 39 & 91.65 & 2.35 & 341.82 & 8.76 & 26.81 & 38.32 & 41.37 & 873.26 & 22.39 \\
\hline 28198 & 79 & 41 & 58.23 & 1.42 & 492.16 & 12.00 & 11.83 & 42.55 & 45.18 & 1884.10 & 45.95 \\
\hline 28215 & 82 & 6 & 115.50 & 19.25 & 512.09 & 85.35 & 22.55 & 46.95 & 46.58 & 4898.59 & 816.43 \\
\hline 28163 & 83 & 41 & 87.64 & 2.14 & 472.26 & 11.52 & 18.56 & 21.58 & 21.13 & 945.10 & 23.05 \\
\hline 28165 & 85 & 39 & 88.57 & 2.27 & 570.77 & 14.64 & 15.52 & 50.17 & 54.17 & 24544.99 & 629.36 \\
\hline 28195 & 85 & 16 & 37.50 & 2.34 & 243.99 & 15.25 & 15.37 & 47.52 & 47.76 & 1070.33 & 66.90 \\
\hline 28204 & 86 & 35 & 94.38 & 2.70 & 772.78 & 22.08 & 12.21 & 43.01 & 39.39 & 14117.80 & 403.37 \\
\hline 28207 & 86 & 41 & 168.29 & 4.10 & 770.05 & 18.78 & 21.85 & 51.90 & 50.49 & 1197.20 & 29.20 \\
\hline 28200 & 87 & 38 & 91.59 & 2.41 & 1205.57 & 31.73 & 7.60 & 31.38 & 30.38 & 32844.71 & 864.33 \\
\hline 28209 & 91 & 25 & 83.96 & 3.36 & 540.01 & 21.60 & 15.55 & 42.04 & 42.73 & 899.14 & 35.97 \\
\hline 28202 & 92 & 26 & 201.65 & 7.76 & 2764.96 & 106.34 & 7.29 & 38.21 & 42.41 & 34555.46 & 1329.06 \\
\hline Mean & 79.44 & 33.56 & 154.86 & 5.26 & 1031.76 & 33.89 & 16.84 & 41.26 & 40.82 & 8803.48 & 297.13 \\
\hline \multicolumn{12}{|l|}{ Males } \\
\hline 28168 & 69 & 41 & 172.14 & 4.20 & 4718.43 & 115.08 & 3.65 & 36.95 & 44.00 & 53515.30 & 1305.25 \\
\hline 28162 & 71 & 41 & 241.20 & 5.88 & 2929.95 & 71.46 & 8.23 & 48.64 & 44.17 & 26493.63 & 646.19 \\
\hline 28166 & 71 & 3 & 452.24 & 150.75 & 2038.71 & 679.57 & 22.18 & 49.84 & 47.99 & 6204.24 & 2068.08 \\
\hline 28177 & 71 & 41 & 137.10 & 3.34 & 1153.77 & 28.14 & 11.88 & 29.84 & 30.03 & 4090.48 & 99.77 \\
\hline 28167 & 72 & 41 & 119.38 & 2.91 & 611.56 & 14.92 & 19.52 & 19.87 & 19.98 & 2453.93 & 59.85 \\
\hline 28210 & 72 & 41 & 69.30 & 1.69 & 463.83 & 11.31 & 14.94 & 31.32 & 29.52 & 2228.59 & 54.36 \\
\hline 28206 & 73 & 27 & 50.64 & 1.88 & 546.65 & 20.25 & 9.26 & 26.60 & 26.56 & 2629.92 & 97.40 \\
\hline 28213 & 74 & 41 & 185.73 & 4.53 & 1357.62 & 33.11 & 13.68 & 53.69 & 51.49 & 3909.59 & 95.36 \\
\hline 28170 & 75 & 39 & 170.97 & 4.38 & 1841.16 & 47.21 & 9.29 & 40.56 & 45.86 & 18335.52 & 470.14 \\
\hline 28173 & 75 & 30 & 368.66 & 12.29 & 2146.95 & 71.57 & 17.17 & 37.11 & 38.65 & 68319.08 & 2277.30 \\
\hline 28160 & 76 & 41 & 80.81 & 1.97 & 556.61 & 13.58 & 14.52 & 21.21 & 20.43 & 1628.48 & 39.72 \\
\hline 28196 & 76 & 37 & 277.81 & 7.51 & 1108.02 & 29.95 & 25.07 & 25.47 & 24.66 & 1906.11 & 51.52 \\
\hline 28216 & 76 & 27 & 117.72 & 4.36 & 550.51 & 20.39 & 21.38 & 52.55 & 51.73 & 720.26 & 26.68 \\
\hline 28208 & 77 & 41 & 59.83 & 1.46 & 383.77 & 9.36 & 15.59 & 30.58 & 30.86 & 1856.58 & 45.28 \\
\hline 28214 & 77 & 41 & 188.55 & 4.60 & 7721.69 & 188.33 & 2.44 & 26.73 & 28.73 & 165552.81 & 4037.87 \\
\hline 28159 & 78 & 31 & 195.71 & 6.31 & 4313.78 & 139.15 & 4.54 & 29.74 & 23.88 & 166533.52 & 5372.05 \\
\hline 28194 & 84 & 41 & 301.15 & 7.35 & 3820.16 & 93.17 & 7.88 & 33.00 & 38.22 & 105794.24 & 2580.35 \\
\hline 28211 & 84 & 41 & 269.19 & 6.57 & 1814.33 & 44.25 & 14.84 & 52.99 & 48.96 & 4733.77 & 115.46 \\
\hline 28158 & 98 & 22 & 556.61 & 25.30 & 2462.38 & 111.93 & 22.60 & 50.53 & 48.31 & 110856.73 & 5038.94 \\
\hline Mean & 76.26 & 35.11 & 211.30 & 13.54 & 2133.68 & 91.72 & 13.61 & 36.69 & 36.53 & 39355.94 & 1288.50 \\
\hline Grand mean & 77.81 & 34.35 & 183.84 & 9.51 & 1597.61 & 63.59 & 15.18 & 38.92 & 38.61 & 24492.58 & 806.22 \\
\hline
\end{tabular}

\section{Substrate-utilisation and movement characteristics}

Of the 40 lobsters tracked during the spring, 29 were observed on substrate hardness $<20$ (14 females and 15 males). Total time spent on substrate $\leq 20$, $\leq 30$, and $\geq 40$ were $8.4,44$ and $38 \%$, respectively. Mean step-speed and mean turning angle ( $\mathrm{n}=$ 72393 ) were plotted for each substrate hardness integer (Fig. 5A and B, respectively). Significant differences in movement characteristics were displayed over 'soft' ground (substrate hardness <18; Fig. 5). Mean step-speed was high and mean turning angle low (high directionality) when lobsters were over soft substrate. Data from the 10 lobsters present during both spring and autumn periods predicted no difference in the distribution of step-speed or turn angle with hardness, between the 2 seasons. Total distance travelled per day, calculated from cumulative steplengths standardised by duration of tracking, showed no correlation with sex or size of the individual. 
Table 2. Summary of home-range statistics (see Table 1) during the autumn study period

\begin{tabular}{|c|c|c|c|c|c|c|c|c|c|c|c|}
\hline ID & $\begin{array}{c}\mathrm{CL} \\
(\mathrm{mm})\end{array}$ & Days & $\begin{array}{l}\text { 50UD } \\
\left(\mathrm{m}^{2}\right)\end{array}$ & $\begin{array}{c}\text { 50UD-d } \\
\left(\mathrm{m}^{2}\right)\end{array}$ & $\begin{array}{l}\text { 95UD } \\
\left(\mathrm{m}^{2}\right)\end{array}$ & $\begin{array}{l}\text { 95UD-d } \\
\left(\mathrm{m}^{2}\right)\end{array}$ & $\begin{array}{c}\text { 50UD:95UD } \\
(\%)\end{array}$ & $\begin{array}{l}\text { 50UD } \\
\text { hard }\end{array}$ & $\begin{array}{l}\text { 95UD } \\
\text { hard }\end{array}$ & $\begin{array}{c}\mathrm{MCP} \\
\left(\mathrm{m}^{2}\right)\end{array}$ & $\begin{array}{c}\mathrm{MCP}-\mathrm{d} \\
\left(\mathrm{m}^{2}\right)\end{array}$ \\
\hline \multicolumn{12}{|l|}{ Females } \\
\hline 28169 & 73 & 30 & 29.41 & 0.98 & 237.08 & 7.90 & 12.40 & 18.00 & 17.53 & 277.50 & 9.25 \\
\hline 28195 & 85 & 22 & 42.13 & 1.92 & 267.23 & 12.15 & 15.77 & 45.06 & 44.53 & 538.62 & 24.48 \\
\hline Mean & 79.00 & 26.00 & 35.77 & 1.45 & 252.16 & 10.02 & 14.09 & 31.53 & 31.03 & 408.06 & 16.87 \\
\hline \multicolumn{12}{|l|}{ Males } \\
\hline 28168 & 69 & 64 & 34.16 & 0.53 & 238.28 & 3.72 & 14.34 & 50.38 & 50.45 & 1749.46 & 27.34 \\
\hline 28177 & 71 & 62 & 138.10 & 2.23 & 685.93 & 11.06 & 20.13 & 40.85 & 37.89 & 1653.77 & 26.67 \\
\hline 28167 & 72 & 51 & 60.37 & 1.18 & 251.03 & 4.92 & 24.05 & 20.49 & 20.44 & 358.27 & 7.02 \\
\hline 28206 & 73 & 64 & 82.81 & 1.29 & 504.33 & 7.88 & 16.42 & 31.52 & 31.60 & 1133.90 & 17.72 \\
\hline 28213 & 74 & 64 & 61.37 & 0.96 & 764.77 & 11.95 & 8.02 & 54.09 & 53.89 & 3368.38 & 52.63 \\
\hline 28196 & 76 & 23 & 147.79 & 6.43 & 784.07 & 34.09 & 18.85 & 41.28 & 39.51 & 1125.39 & 48.93 \\
\hline 28216 & 76 & 17 & 58.46 & 3.44 & 378.87 & 22.29 & 15.43 & 48.44 & 48.72 & 548.14 & 32.24 \\
\hline 28208 & 77 & 62 & 84.59 & 1.36 & 439.21 & 7.08 & 19.26 & 32.96 & 32.15 & 1375.34 & 22.18 \\
\hline Mean & 73.50 & 50.88 & 83.46 & 2.18 & 505.81 & 12.87 & 17.06 & 40.00 & 39.33 & 1414.08 & 29.34 \\
\hline Grand mean & 74.60 & 45.90 & 73.92 & 2.03 & 455.08 & 12.30 & 16.47 & 38.31 & 37.67 & 1212.88 & 26.85 \\
\hline
\end{tabular}
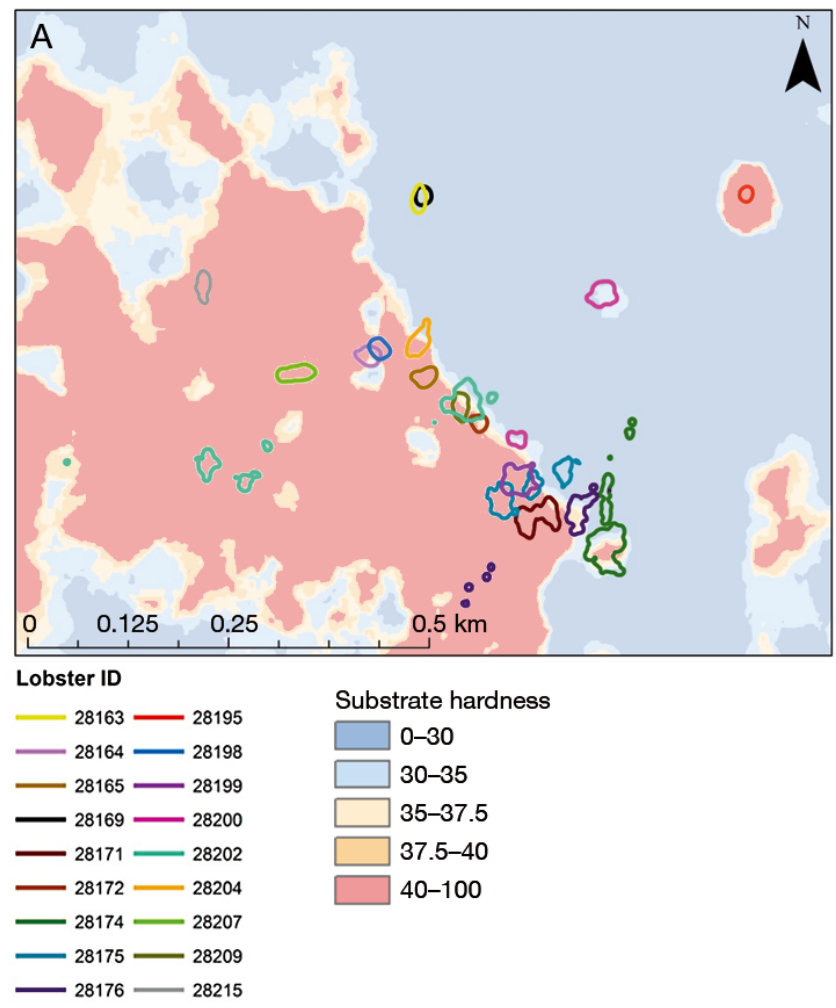
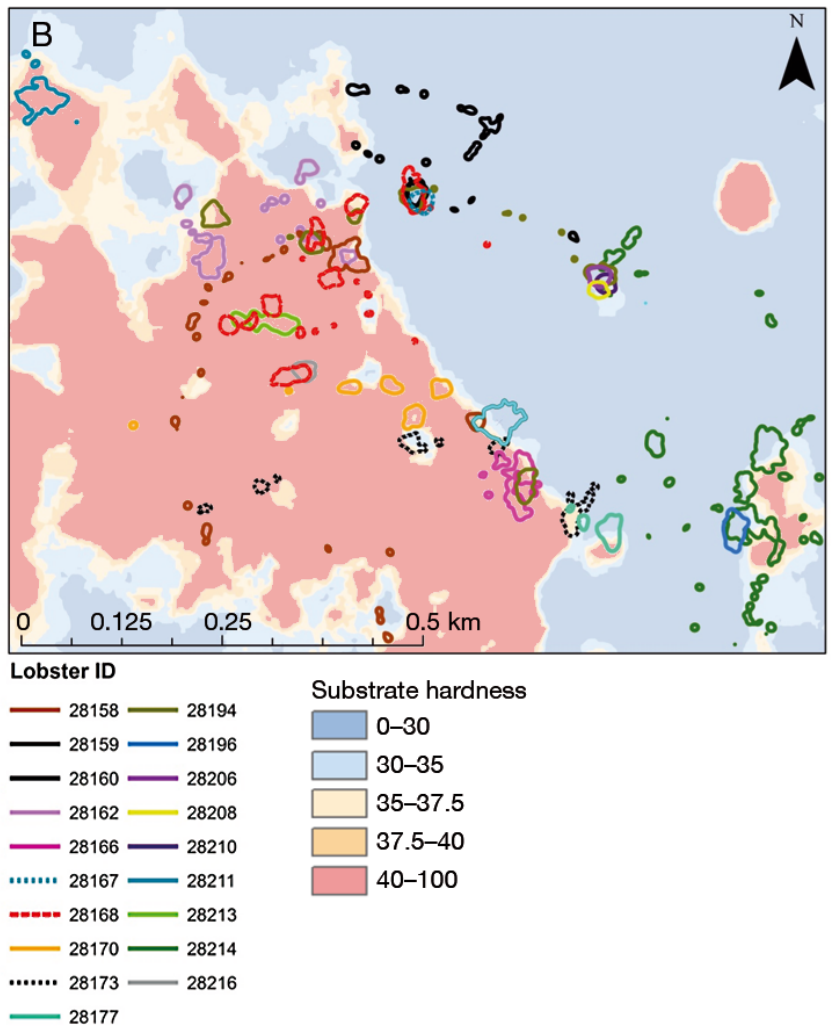

Fig. 3. $95 \%$ utilisation distribution (95UD) home-ranges of (A) 18 female and (B) 19 male European lobsters during the spring study period

\section{Activity patterns}

Hourly spring detection ratios between animal tags and synctags indicated significant diurnal variation in activity (Kruskal-Wallis 1 : $\chi^{2}=278.53, \mathrm{p}<$ $0.001)$; lobsters were most active between 19:00 and
07:00 h (Fig. 6). Autumn hourly detection ratios were also significantly different from one another (Kruskal-Wallis $1: \chi^{2}=19.4261, \mathrm{p} \leq 0.001$ ); however, diel patterns of activity were not as clear as during the spring (Fig. 6). There were no significant differences between day and night for mean hardness, 


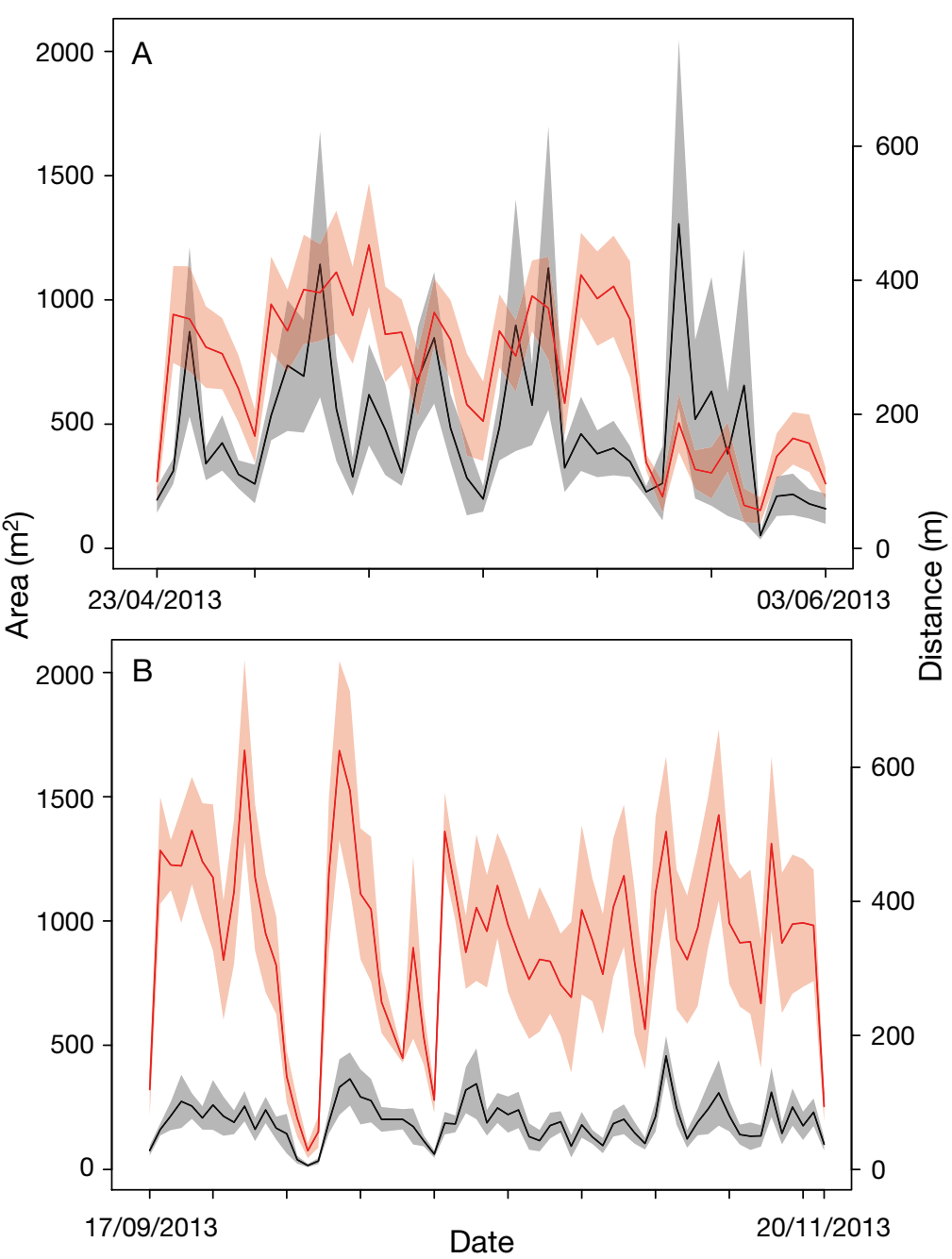

Fig. 4. Mean daily home-range area estimated by minimum convex polygons (black, left $y$-axis) and mean daily cumulative step-length (i.e. distance; red, right $y$-axis) for the 10 European lobsters present during the (A) spring and (B) autumn study period, including standard error (shading). $x$-axis tick marks indicate weeks. Dates given $d / m o / y r$

Table 3. Mean ( \pm SE) home-range statistics for lobsters observed during both periods $(\mathrm{n}=10) ; 50 \%$ and $95 \%$ utilisation distribution (50UD and 95UD) area and substrate hardness

\begin{tabular}{|lcccc|}
\hline & 50UD $\left(\mathrm{m}^{2}\right)$ & 95UD $\left(\mathrm{m}^{2}\right)$ & 50UD hard & 95UD hard \\
\hline Spring & $124.41 \pm 22.00$ & $11103.93 \pm 397.43$ & $34.33 \pm 3.83$ & $34.46 \pm 3.93$ \\
Autumn & $73.92 \pm 12.22$ & $455.08 \pm 66.13$ & $38.31 \pm 3.69$ & $37.67 \pm 3.70$ \\
\hline
\end{tabular}

\section{DISCUSSION}

The results presented here are, to our knowledge, the first descriptions of highresolution movement and behaviour of individual Homarus gammarus in their natural habitat (Fig. 2). While there have been 4 previous studies tracking $H$. gammarus, that have successfully described diel activity patterns (Smith et al. 1998, 1999), differences between native and transplanted lobsters (van der Meeren 1997) and long-term movement and home-ranges (Moland et al. 2011a, Wiig et al. 2013), none of the previous approaches were capable of accurately defining movement, substrate-utilisation or differences between sexes. One of the strongest aspects of the present study, was the large sample size $(n=44)$, which lends itself to more accurate use of KDE for home-range estimation (Millspaugh \& Marzluff 2001). The ratio of tagged males and females enabled sex effects on movement and behaviour to be fully explored. While the relatively small size of the study area made it possible to log high resolution data with high detection rates, it prevented observations of large-scale movements, and home-ranges were underestimated for some transient lobsters. Future studies should increase the temporal and spatial resolution to help improve understanding of emigration and connectivity between substrate patches.

\section{Home-range}

Reported home-ranges were relatively small; mean spring 95UD of 1032 and $2134 \mathrm{~m}^{2}$ for females and males, respectively. Previous studies report larger $H$. gammarus home-range estimates; Wiig et al. (2013) reported a mean September 95UD male home-range of $170660 \mathrm{~m}^{2}$, declining to $123004 \mathrm{~m}^{2}$ dur-

male and female activity, or substrate-use of males and females. The range of hardness for positions was significantly different between day and night for all lobsters (Wilcoxon 78 : $V=232, \mathrm{p}<0.02$ ), with a wider range of substrate being used during the night. ing October and November. While, over the course of a year, Moland et al. (2011a) reported a mean 95UD home-range of $19879 \mathrm{~m}^{2}$. Previous studies used different methodologies and worked in wider spatial scales from the present study. Moland et al. (2011a) also worked over a much wider temporal scale, 

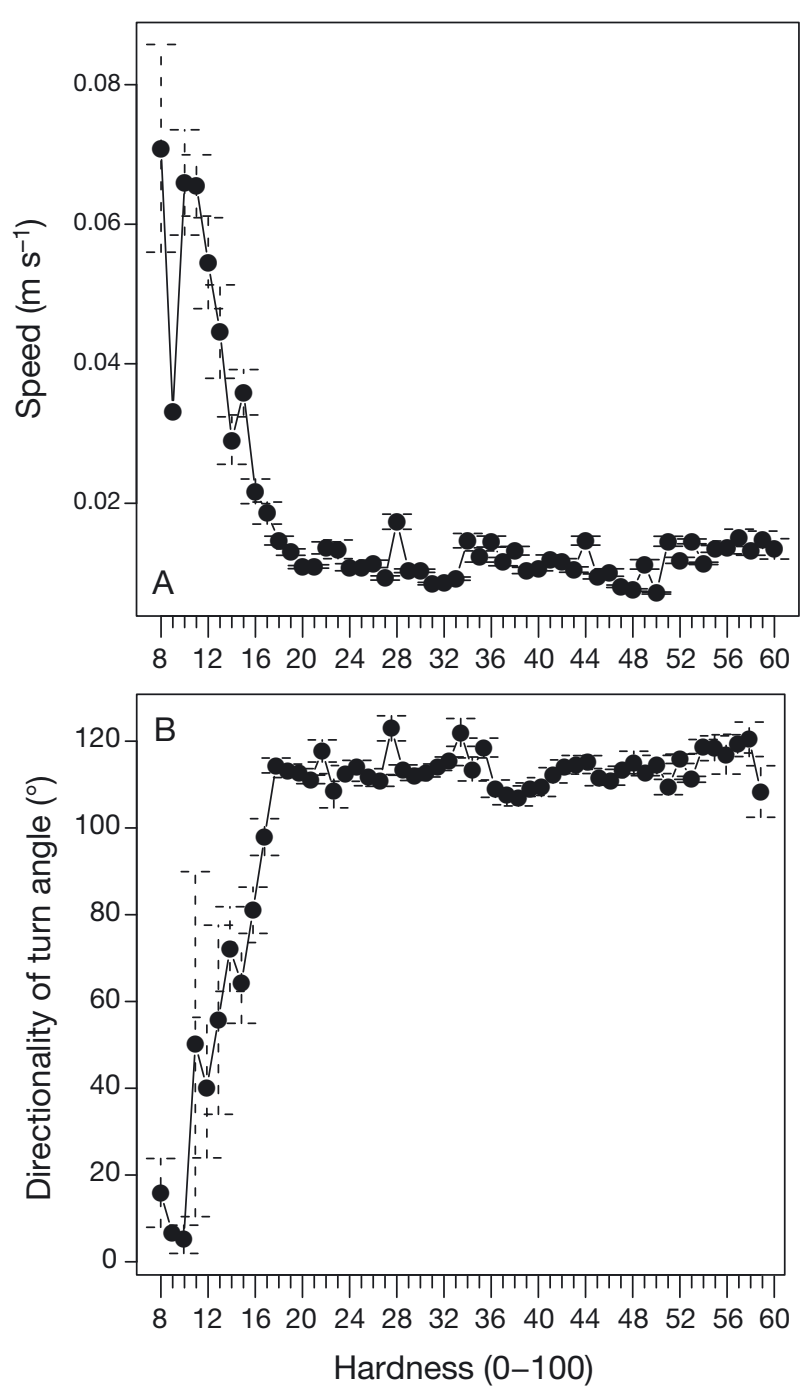

Fig. 5. Mean $( \pm 95 \%$ CI) (A) step-speed $(n=72395)$ and $(B)$ turning angle $(\mathrm{n}=72393)$ between all consecutive points, across spring and autumn categorised by the underlying substrate hardness

whereas here we focussed on short-term, fine-scale movement within a restricted study area.

Moland et al. (2011a) found that it took, on average, 98 and $259 \mathrm{~d}$ to reach 50 and $95 \%$ of the annual $\mathrm{MCP}$, respectively. Therefore, lobsters emigrating from our study site may have had home-ranges larger than the area covered by the array. Increasing the extent of the array, the length of the study period and/or tracking emigrants as they move outwith the array would help resolve this. Furthermore, the present study used TDOA within a VPS to gain positions rather than daily fixes via mobile tracking (Moland et al. 2011a) or 30 min centres of activity within a VR2W array (Simpfendorfer et al. 2002, Wiig et al. 2013); the latter approach would have caused home-ranges to

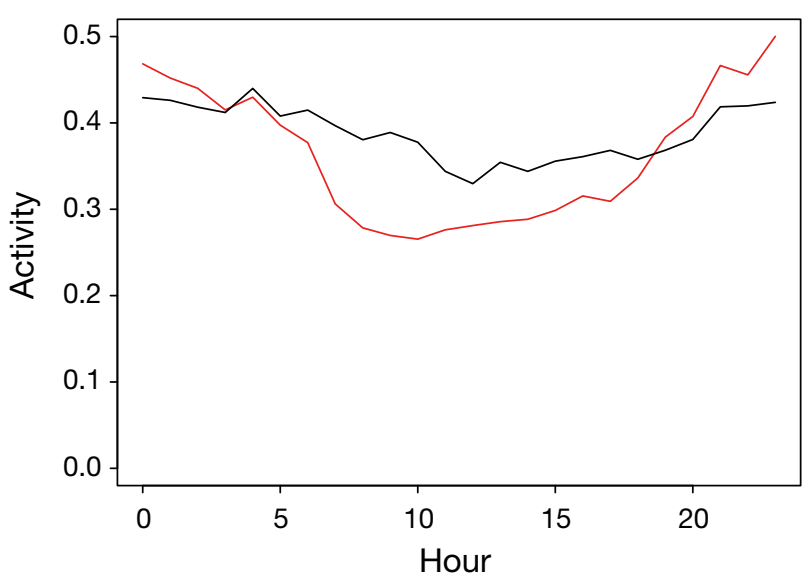

Fig. 6. Lobster activity, displayed as a ratio of lobster tag detection frequency to synctag detection frequency, for all European lobsters during spring (red) and autumn (black), categorised into a continuous metric from 0 to $24 \mathrm{~h}$ that represent hourly bins from 00:00-00:59 h to 23:00-23:59 h

be overestimated. The present data are highly accurate within this spatial and temporal context but will likely have underestimated transient and migrating lobsters' home-ranges, while the previous studies likely overestimated lobster home-ranges, particularly of residents. However, methodological differences do not exclude the possibility of biological or behavioural differences between lobsters in the present (UK) and previous studies (Norway). The Norwegian lobster fishery has a 10 mo closed season to fishing, is characterised by much lower commercial landings (ICES 2012) and the habitat and environment is very different to the present; this may be conducive to increased individual range of movement.

The work of Moland et al. (2011a), Smith et al. (2001) and Agnalt et al. (2007) suggests that H. gammarus have restricted dispersal and lower movement rates than $H$. americanus (Dow 1974, Fogarty et al. 1980, Campbell \& Stasko 1985, 1986, Smith et al. 2001, Agnalt et al. 2007, Moland et al. 2011a). However, the present data are similar to a VPS study of short-term (ca. 4 d) H. americanus movements, where mean 95UD home-range was $760 \mathrm{~m}^{2}$ (Scopel et al. 2009). This supports the hypothesis that methodology, study duration and area influence homerange estimations.

Previous studies have not found relationships between body size or sex, and home-range size (Gherardi \& Cioni 2004, Golet et al. 2006, Scopel et al. 2009, Moland et al. 2011a, Wiig et al. 2013). However, studies to date have sampled only a limited range of body size or only male $H$. gammarus. While this study also found no correlation with CL and 
home-range, detections indicate that male lobsters had larger home-ranges than female lobsters (Table 1). While both sexes conduct the majority of their activities within similar areas, male lobsters had a greater propensity for travelling further from shelter and were more likely to have multiple 95UD cores. The breadth of home-range estimates for all animals highlights high individual variation in lobster space-use. This adds credence to hypotheses that populations are governed by individual 'personalities traits' in the form of variation in boldness, habitat-use, exploration and movement (Fraser et al. 2001, Golet et al. 2006, Wolf et al. 2007, Scopel et al. 2009, McMahan et al. 2013b), which in turn are likely governed by environment and individual fitness. The complexity of individual behaviour and high intrapopulation variation requires high repetition and large cohorts of tagged animals in telemetry.

KDE home-range estimation is an area of potential error in these analyses. An often cited drawback is the choice of search radius (h) (Worton 1995, Seaman \& Powell 1996, Kernohan et al. 2001), which aims to reduce variability at the cost of increasing bias (Fieberg 2007). To ensure individual home-ranges were comparable, $h$ was fixed at $7.6 \mathrm{~m}$; this biased some estimates upwards and others downwards (introducing fragmentation; Fig. 3). The present selection of $h$ is low in comparison to previous studies (Wiig et al. (2013): $h=50$, Moland et al. (2011a): $h=$ 25), but appropriate given the temporal and spatial scale, accuracy and detection frequency of the method (Fieberg 2007). Positional fixes (re-sightings) within $h(7.6 \mathrm{~m})$ should only occur if the animal choses to remain or returns to that area; therefore, $7.6 \mathrm{~m}$ is appropriate given that a lobster could walk ca. $7.5 \mathrm{~m}$ during the smallest detection interval. The present study gained up to 1 position every $10 \mathrm{~min}$, requiring a much smaller value for $h_{i}$ using a larger search radius would calculate 95UD home-ranges that extend into area locations not identified by the data (Walter et al. 2011).

It should also be noted, that due to AT requiring approximate line-of-sight between receivers and transmitters, positions are generally recorded while the lobsters are outside of shelter. This means that UD home-ranges reported here are for periods when lobsters are outside of shelter and will not represent a true reflection of probabilistic distribution (this does not influence MCP estimates), but positional data does reflect true space-utilisation. Continuous tracking data with constant interval rates would be required to understand their true probabilistic distribution.

\section{Seasonality}

This study highlights the seasonality of movement behaviour. All home-range area estimates, except for 50UD, significantly reduced during autumn (Fig. 2, Table 4). This implies that short movements away from shelter and near-by foraging remain vital. However, large excursions from shelter were restricted and fragmented home-ranges were not observed during autumn, perhaps as potential gains to fitness of large excursions are outweighed by potential losses (Levin et al. 1984, Miller et al. 1985). However, it could also be an artefact of the methodology as animals available for tracking during both study periods, by definition, exhibited non-transient behaviour. Therefore, seasonal comparisons are biased towards individuals with restricted movement. However, they still provide an insightful, and direct, comparison of paired seasonal home-range data.

Reduced space-use during autumn is perhaps surprising as lobsters are considered nocturnal and must behaviourally regulate their body temperature (Crossin et al. 1998). Autumn was characterised by greater temperatures and shorter day-lengths; therefore,

Table 4. Summary of statistics for paired $t$-tests of seasonal comparison of daily minimum convex polygon (MCP) values and daily cumulative step-length for individual lobsters ( $\mathrm{n}=$ $10)$ and mean daily values of all lobsters. Greater values of significant difference $(p<0.05)$ in bold

\begin{tabular}{|lcrrrc|}
\hline ID & Spring & Autumn & df & $t$ & $\mathrm{p}$ \\
\hline MCP & & & & & \\
28167 & $\mathbf{8 4 1 . 3 4}$ & 30.02 & 68 & 5.27 & $<0.01$ \\
28168 & $\mathbf{7 2 6 . 3 9}$ & 118.09 & 100 & 2.84 & $<0.01$ \\
28169 & $\mathbf{4 0 1 . 3 8}$ & 13.52 & 57 & 3.80 & $<0.01$ \\
28177 & $\mathbf{5 5 9 . 1 2}$ & 322.96 & 83 & 2.16 & $<0.01$ \\
28195 & $\mathbf{1 8 2 . 9 9}$ & 96.16 & 63 & 2.86 & $<0.01$ \\
28196 & 693.2 & 329.99 & 49 & 1.15 & 0.25 \\
28206 & $\mathbf{2 9 1 . 6 1}$ & 78.65 & 84 & 6.73 & $<0.01$ \\
28208 & $\mathbf{2 8 8 . 5 3}$ & 186.55 & 102 & 2.72 & $<0.01$ \\
28213 & $\mathbf{7 3 9 . 4 6}$ & 451.47 & 99 & 2.14 & $<0.05$ \\
28216 & 157.04 & 146.08 & 32 & 0.21 & 0.80 \\
All lobsters & $\mathbf{4 8 4 . 8 5}$ & 194.17 & 104 & 7.68 & $<0.01$ \\
Step-length & & & & & \\
28167 & $\mathbf{3 9 7 . 4 9}$ & 75.35 & 68 & 5.90 & $<0.01$ \\
28168 & 178.5 & $\mathbf{2 9 6 . 2 5}$ & 100 & -3.62 & $<0.01$ \\
28169 & $\mathbf{4 2 3 . 9 4}$ & 28.11 & 57 & 7.51 & $<0.01$ \\
28177 & 134.85 & $\mathbf{3 8 3 . 9 2}$ & 83 & -3.95 & $<0.01$ \\
28195 & $\mathbf{3 1 4 . 4 8}$ & 175.31 & 63 & 2.86 & $<0.01$ \\
28196 & 159.77 & $\mathbf{4 1 3 . 7 4}$ & 49 & -3.30 & $<0.01$ \\
28206 & $\mathbf{3 2 6 . 9 2}$ & 198.48 & 84 & 2.62 & $<0.01$ \\
28208 & 236.01 & $\mathbf{4 8 0 . 6}$ & 102 & -6.35 & $<0.01$ \\
28213 & 297.6 & $\mathbf{7 5 0 . 3}$ & 99 & -8.36 & $<0.01$ \\
28216 & 88.21 & $\mathbf{2 2 7 . 9 7}$ & 32 & -2.63 & $<0.01$ \\
All lobsters & 260.45 & $\mathbf{3 4 7 . 7 3}$ & 104 & -3.56 & $<0.01$ \\
\hline & & & & & \\
\hline
\end{tabular}


warmer and longer periods of darkness would be expected to produce increased movement and spaceuse. Further insights were gained from the analysis of daily MCP and daily step-length, and seasonal hourly activity patterns. These suggests that while lobsters reduced their space-utilisation during the autumn, in opposition to the hypothesis, they were more 'active'; on average moving further each day (Fig. 4) and remaining outside of shelter for longer periods (Fig. 6), in agreement with the hypothesis. We suspect this behavioural change is linked to an increase in local abundance of suitable prey during autumn as benthic prey abundance is assumed to be positively correlated with water temperature (Beukema 1990). This increase in prey availability may allow lobsters to gain the energy required during shorter distance forays from shelter than during spring. Regarded as a cryptic and somewhat sedentary species, large movements from shelter are probably only undertaken when forced by prey-, mate-, or shelter-shortages (Croft et al. 2003, Pittman \& McAlpine 2003, Austin et al. 2004, Edgar et al. 2004, Bowler \& Benton 2005, Darden \& Croft 2008). This highlights the danger of relying solely on homerange analysis as an indication of activity or movement behaviour.

\section{Movement characteristics and substrate-utilisation}

Mobility has previously been shown to correlate positively with catchability and a propensity for increased trap interaction (Bowlby et al. 2007, Wiig et al. 2013). The reduced space-utilisation of animals during the autumn could explain seasonal reductions in lobster landings (Bennett 1974a). Results also suggest that male lobsters have a higher catchability, due to their larger 95UD home-ranges and the increased degree of fragmentation. Findings highlight potential issues with studies using traps to catch animals for samples, which could be biased towards individuals with higher catchability, and prone to disperse, rather than resident animals exhibiting smaller home-ranges. $H$. americanus have been categorised into 2 movement groups; transient and resident (Cooper \& Uzmann 1980, Ennis 1984b, Karnofsky et al. 1989, Bowlby et al. 2007, Geraldi et al. 2009, Scopel et al. 2009). To date there is no definitive evidence for this dichotomous behaviour in $H$. gammarus, but it is thought to occur (Dybern et al. 1967, Dybern 1973, Smith et al. 1999, Moland et al. 2011a,b). Residents are characterised as remaining within the area of release whereas transients move rapidly from the release site (Pezzack \& Duggan 1986, Geraldi et al. 2009). This behaviour has not been explained by size or sex and is likely an individual's response to environmental limitations (Bowlby et al. 2007), reflecting a trade-off in response to current health, reproductive stage, moult stage, local food, shelter and mate availability (Ennis 1984a,b, Atema 1986, Dieckmann et al. 1999). Both residents and transient lobsters were observed in this study (Fig. 2), with 10 animals remaining in the study area for the entire period, while others migrated outside within the first week, used several home-ranges throughout the study area or of which detection was lost. Understanding why behaviours change between resident and transient individuals is key to understanding and defining their movements.

Long-distance exploratory movements in H. gammarus have been recorded albeit infrequently (Jensen et al. 1994), highlighting potential connectivity between discrete areas of lobster habitat. Selection would be expected to favour the least energetically expensive mode of movement (Zollner \& Lima 1999) via soft substrate corridors (Beier \& Noss 1998, Micheli \& Peterson 1999, Hovel \& Lipcius 2001). Utilisation of soft substrate was regularly recorded in this study, with movement path metrics (step-speed and turning angle) showing statistically significant changes over soft substrate (hardness values between 0 and 20). Increased speed and directionality could reflect risks inherent in movement over unstructured soft substrate due to increased susceptibility to predation (Spanier et al. 1998, Micheli \& Peterson 1999, Gilliam \& Fraser 2001, Hovel \& Wahle 2010). Fast, highly directional movement towards shelter-providing substrate is expected. Movement on hard, substrate will require larger turning angles and slower speeds due to the difficulties of traversing this substrate (Schippers et al. 1996, Wiens et al. 1997). However, as this is a non-linear response, it may also indicate increased foraging or searching behaviour (Skajaa et al. 1998, Watson et al. 1999, Patterson et al. 2008). These findings suggest that population assessments will benefit from considering benthic composition and the likely resulting context specific behaviour of individuals. Clear discrimination between behaviours over soft and hard substrates by the present study highlights a key advantage of AT technology over trap-based methods. AT does not require the animal to be in a feeding state to be observed. Movement types have previously been identified as: intensive search movements, characterised by short step lengths and low directionality of turning angles; and exploratory movement where 
step lengths are long and have high directionality (Martin et al. 2009). Applying these principles to this study suggests that lobsters are conducting exploratory behaviour over soft sediment and therefore may be less likely to approach a baited trap.

\section{CONCLUSION}

This study demonstrates the capabilities of a fixed AT VPS array for quantifying fine-scale movements of marine animals within a heterogeneous study site. It provides the first AT study of European lobsters using hyperbolic positioning, informing future application of the technique. Several challenges were faced during the deployment and analysis of the VPS data. Reducing movement of the receivers was essential; thus, we moored the receivers to sub-surface markers. Furthermore, positioning the array was a trade-off between area covered and accuracy, and in future we would suggest increasing the spatial and temporal extent of VPS studies. Future studies should also ensure that verification of the animals' condition is conducted; it was not possible during this study, and analysis comparing animal tags against synctags to justify the tags being attached to living lobsters was a laborious process.

In contrast to previous studies, males displayed greater short-term exploratory behaviour than females, with greater and more fragmented 95UD home-ranges and a tendency to use a wider range of substrata. No significant effect of size was observed, but seasonal and diel cycles were important in determining behaviour. One of the most striking results from this study was the reduction in size of homerange of all lobsters during the autumn period. If observed in isolation, this could be deemed a reduction in movement and activity, however, coupled with expansion of activity across the diel cycle and greater daily movement rates during autumn than in spring. This highlights a potential issue arising from attempts to interpret positional data using homerange analysis alone.

These data illustrate the presence of both resident and transient lobster within the tagged population. Understanding the complexity of individual responses to the environment (e.g. site fidelity) is the greatest challenge in translating these data for managers of the fisheries. Behavioural decisions are complex and may be driven by numerous variables, including fitness and intra- and inter-specific interactions, not necessarily biometric measurements of sex or size. This study has demonstrated the ability of AT to pro- vide essential data on spatial structure of fine-scale lobster movements and shows its potential for intricate behavioural work with marine species in the future.

Acknowledgements. The analysis and preparation of this publication was made possible through the generous support of the Fish and Fisheries Committee within the Fishmongers' Company. Data collection was funded by the Marine Management Organisation's Fisheries Challenge Fund (FES-289), in partnership with Northumberland Inshore Fisheries and Conservation Authority (NIFCA) and Newcastle University. The authors thank all those from NIFCA, including those who helped with the collection of samples and data. We also thank the crew of the RV 'Princess Royal'; Dr. Ben Whigham, Neil Armstrong, Barry Pearson and Peter Berney, for assistance and support in the field; VEMCO, particularly Dr. Dale Webber for guidance during the initial stages of the project; and finally Dr. Even Moland for advice and motivation. The manuscript was greatly improved after feedback from 3 anonymous reviewers.

\section{LITERATURE CITED}

Addison JT (1995) Influence of behavioural interactions on lobster distribution and abundance as inferred from potcaught samples. ICES Mar Sci Symp 199:294-300

Addison JT (1997) Lobster stock assessment: report from a workshop; I. Mar Freshw Res 48:941-944

> Agnalt AL, Kristiansen TS, Jorstad KE (2007) Growth, reproductive cycle, and movement of berried European lobsters (Homarus gammarus) in a local stock off southwestern Norway. ICES J Mar Sci 64:288-297

Andrews KS, Tolimieri N, Williams GD, Samhouri JF, Harvey CJ, Levin PS (2011) Comparison of fine-scale acoustic monitoring systems using home range size of a demersal fish. Mar Biol 158:2377-2387

Atema J (1986) Review of sexual selection and chemical communication in the lobster, Homarus americanus. Can J Fish Aquat Sci 43:2283-2290

Austin D, Bowen WD, McMillan JI (2004) Intraspecific variation in movement patterns: modeling individual behaviour in a large marine predator. Oikos 105:15-30

Beier P, Noss RF (1998) Do habitat corridors provide connectivity? Conserv Biol 12:1241-1252

Bennett DB (1974a) The effects of pot immersion time on catches of crabs, Cancer pagurus (L.) and lobsters, Homarus gammarus (L.). J Cons Int Explor Mer 35:332-336

Beukema JJ (1990) Expected effects of changes in winter temperatures on benthic animals living in soft sediments in coastal North Sea areas. In: Beukema JJ, Wolff WJ, Brouns JJWM (eds) Expected effects of climatic change on marine coastal ecosystems. Springer, Dordrecht, p 83-92

> Börger L, Dalziel BD, Fryxell JM (2008) Are there general mechanisms of animal home range behaviour? A review and prospects for future research. Ecol Lett 11:637-650

> Bowlby HD, Hanson JM, Hutchings JA (2007) Resident and dispersal behavior among individuals within a population of American lobster Homarus americanus. Mar Ecol Prog Ser 331:207-218

Bowler DE, Benton TG (2005) Causes and consequences of 
animal dispersal strategies: relating individual behaviour to spatial dynamics. Biol Rev Camb Philos Soc 80: 205-225

Campbell A, Stasko AB (1985) Movements of tagged American lobsters, Homarus americanus, off southwestern Nova Scotia. Can J Fish Aquat Sci 42:229-238

Campbell A, Stasko AB (1986) Movements of lobsters (Homarus americanus) tagged in the Bay of Fundy, Canada. Mar Biol 92:393-404

> Chang JH, Chen Y, Holland D, Grabowski J (2010) Estimating spatial distribution of American lobster Homarus americanus using habitat variables. Mar Ecol Prog Ser 420:145-156

Coates JH, Hovel KA, Butler JL, Klimley AP, Morgan SG (2013) Movement and home range of pink abalone Haliotis corrugata: implications for restoration and population recovery. Mar Ecol Prog Ser 486:189-201

Conner LM, Plowman BW (2001) Using Euclidean distances to assess nonrandom habitat use. In: Millspaugh JJ, Marzluff JM (eds) Radio tracking and animal populations. Academic Press, San Diego, CA, p 275-290

Cooper RA, Uzmann JR (1980) Ecology of juvenile and adult Homarus. In: Cobb JS, Phillips BF (eds) The biology and management of lobsters, Vol 2. Academic Press, New York, NY, p 97-142

Cowan DF, Watson WH III, Solow AR, Mountcastle AM (2007) Thermal histories of brooding lobsters, Homarus americanus, in the Gulf of Maine. Mar Biol 150:463-470

Croft DP, Albanese B, Arrowsmith BJ, Botham M, Webster M, Krause J (2003) Sex-biased movement in the guppy (Poecilia reticulata). Oecologia 137:62-68

Crossin G, Al-Ayoub S, Jury S, Howell W (1998) Behavioral thermoregulation in the American lobster Homarus americanus. J Exp Biol 201:365-374

Darden SK, Croft DP (2008) Male harassment drives females to alter habitat use and leads to segregation of the sexes. Biol Lett 4:449-451

> Di Lorenzo M, D'Anna G, Badalamenti F, Giacalone VM, Starr RM, Guidetti P (2014) Fitting the size of no-take zones to species movement patterns: a case study on a Mediterranean seabream. Mar Ecol Prog Ser 502: 245-255

> Dieckmann U, O'Hara B, Weisser W (1999) The evolutionary ecology of dispersal. Trends Ecol Evol 14:88-90

Dow RL (1974) American lobster tagged by Maine commercial fishermen, 1957-59. Fish Bull 72:622-623

> Dybern BI (1973) Lobster burrows in Swedish waters. Helgol Wiss Meeresunters 24:401-414

Dybern BI, Jacobsson L, Hallbäck H (1967) On the habitat behaviour of the lobster (Homarus vulgaris) in Swedish waters. Meddn Havsfisklab Lysekil 36:1-7

Edgar GJ, Barrett NS, Morton AJ (2004) Patterns of fish movement on eastern Tasmanian rocky reefs. Environ Biol Fishes 70:273-284

Elvenes S, Dolan MFJ, Buhl-Mortensen P, Bellec VK (2014) An evaluation of compiled single-beam bathymetry data as a basis for regional sediment and biotope mapping. ICES J Mar Sci 71:867-881

Ennis GP (1984a) Incidence of molting and spawning in the same season in female lobsters, Homarus americanus. Fish Bull 82:529-530

Ennis GP (1984b) Small-scale seasonal movements of the American lobster Homarus americanus. Trans Am Fish Soc 113:336-338

Fieberg J (2007) Kernel density estimators of home range: smoothing and the autocorrelation red herring. Ecology 88:1059-1066

Fogarty MJ, Addison JT (1997) Modelling capture processes in individual traps: entry, escapement and soak time. ICES J Mar Sci 54:193-205

Fogarty MJ, Borden DVD, Russell HJ (1980) Movements of tagged American lobster, Homarus americanus, off Rhode Island. Fish Bull 78:771-780

> Fraser DF, Gilliam JF, Daley MJ, Le AN, Skalski GT (2001) Explaining leptokurtic movement distributions: intrapopulation variation in boldness and exploration. Am Nat 158:124-135

Galparsoro I, Borja A, Bald J, Liria P, Chust G (2009) Predicting suitable habitat for the European lobster (Homarus gammarus), on the Basque continental shelf (Bay of Biscay), using ecological-niche factor analysis. Ecol Model 220:556-567

Geraldi NR, Wahle RA, Dunnington M (2009) Habitat effects on American lobster (Homarus americanus) movement and density: insights from georeferenced trap arrays, seabed mapping, and tagging. Can J Fish Aquat Sci 66: $460-470$

- Gherardi F, Cioni A (2004) Agonism and interference competition in freshwater decapods. Behaviour 141: 1297-1324

Gilliam JF, Fraser DF (2001) Movement in corridors: enhancement by predation threat, disturbance, and habitat structure. Ecology 82:258-273

Golet WJ, Scopel DA, Cooper AB, Watson III WH (2006) Daily patterns of locomotion expressed by American lobsters (Homarus americanus) in their natural habitat. J Crustac Biol 26:610-620

> Guerra-Castro E, Carmona-Suarez C, Conde JE (2011) Biotelemetry of crustacean decapods: Sampling design, statistical analysis, and interpretation of data. Hydrobiologia 678:1-15

> Hilborn R, Walters CJ (1992) Quantitative fisheries stock assessment: choice, dynamics and uncertainty. Rev Fish Biol Fish 2:177-178

> Holmes KW, Van Niel KP, Radford B, Kendrick GA, Grove SL (2008) Modelling distribution of marine benthos from hydroacoustics and underwater video. Cont Shelf Res 28: 1800-1810

Hovel KA, Lipcius RN (2001) Habitat fragmentation in a seagrass landscape: patch size and complexity control blue crab survival. Ecology 82:1814-1829

Hovel KA, Wahle RA (2010) Effects of habitat patchiness on American lobster movement across a gradient of predation risk and shelter competition. Ecology 91:1993-2002

> Howard AE (1980) Substrate controls on the size composition of lobster (Homarus gammarus) populations. J Cons Int Explor Mer 39:130-133

ICES (International Council for the Exploration of the Sea) (2012) ICES catch statistics 2006-2012. ICES, Copenhagen. http://icesdk/marine-data/dataset-collections/ Pages/Fish-catch-and-stock-assessmentaspx (accessed 6 January 2015)

Jensen AC, Collins KJ, Free EK, Bannister RCA (1994) Lobster (Homarus gammarus) movement on an artificial reef: the potential use of artifcial reefs for stock enhancement. Crustaceana 67:198-211

Jørstad KE, Prodöhl PA, Agnalt AL, Hughes M and others (2004) Sub-arctic populations of European lobster, Homarus gammarus, in northern Norway. Environ Biol Fish 69:223-231 
Kahler TH, Roni P, Quinn TP (2001) Summer movement and growth of juvenile anadromous salmonids in small western Washington streams. Can J Fish Aquat Sci 58: 1947-1956

Karnofsky EB, Atema J, Elgin RH (1989) Field observations of social-behaviour, shelter use, and foraging in the lobster, homarus americanus. Biol Bull 176:239-246

Kernohan BJ, Gitzen RA, Millspaugh JJ, Millspaugh JJ, Marzluff JM (2001) Analysis of animal space use and movements. In: Millspaugh JJ, Marzluff JM (eds) Radio tracking and animal populations. Academic Press, San Diego, CA, p 125-166

- Kie JG, Matthiopoulos J, Fieberg J, Powell RA and others (2010) The home-range concept: Are traditional estimators still relevant with modern telemetry technology? Philos Trans R Soc Lond B Biol Sci 365:2221-2231

> Levin SA, Cohen D, Hastings A (1984) Dispersal strategies in patchy environments. Theor Popul Biol 26:165-191

Lindholm J, Auster PJ, Knight A (2007) Site fidelity and movement of adult Atlantic cod Gadus morhua at deep boulder reefs in the western Gulf of Maine, USA. Mar Ecol Prog Ser 342:239-247

> MacArthur LD, Babcock RC, Hyndes GA (2008) Movements of the western rock lobster (Panulirus cygnus) within shallow coastal waters using acoustic telemetry. Mar Freshw Res 59:603-613

Marine Management Organisation (2013) UK Sea Fisheries Statistics 2012. www.gov.uk/government/statistical-datasets/uk-sea-fisheries-annual-statistics-2012 (accessed 5 January 2015)

Martin J, Tolon V, Van Moorter B, Basille M, Calenge C (2009) On the use of telemetry in habitat selection studies. Barcula D, Daniels J (eds) Telemetry: research, technology and applications. Nova Science Publishers, New York, NY, p 37-55

> Mathies NH, Ogburn MB, McFall G, Fangman S (2014) Environmental interference factors affecting detection range in acoustic telemetry studies using fixed receiver arrays. Mar Ecol Prog Ser 495:27-38

McMahan MD, Brady DC, Cowan DF, Grabowski JH, Sherwood GD, Jech JM (2013a) Using acoustic telemetry to observe the effects of a groundfish predator (Atlantic cod, Gadus morhua) on movement of the American lobster (Homarus americanus). Can J Fish Aquat Sci 70 : 1625-1634

McMahan MD, Brady DC, Cowan DF, Grabowski JH, Sherwood GD, Jech JM (2013b) Using acoustic telemetry to observe the effects of a groundfish predator (Atlantic cod, Gadus morhua) on movement of the American lobster (Homarus americanus) 1. Can J Fish Aquat Sci 70: 1625-1634

Mercer JP, Bannister RCA, van der Meeren GI, Debuse V and others (2001) An overview of the LEAR (Lobster Ecology and Recruitment) project: results of field and experimental studies on the juvenile ecology of Homarus gammarus in cobble. Mar Freshw Res 52:1291-1301

Micheli F, Peterson CH (1999) Estuarine vegetated habitats as corridors for predator movements. Conserv Biol 13: 869-881

Miller JM, Crowder LB, Moser ML (1985) Migration and utilization of estuarine nurseries by juvenile fishes: an evolutionary perspective. Contrib Mar Sci 27(Suppl): 338-352

Millspaugh JJ, Marzluff JM (2001) Radio tracking and animal populations. Academic Press, San Diego, CA
Misra P, Enge P (2006) Global Positioning System: signals, measurements and performance. Ganga-Jamuna Press, Lincoln, MA

> Mohr CO (1947) Table of equivalent populations of North American small mammals. Am Midl Nat 37:223-249

Moland E, Olsen EM, Andvord K, Knutsen JA, Stenseth NC (2011a) Home range of European lobster (Homarus gammarus) in a marine reserve: implications for future reserve design. Can J Fish Aquat Sci 68:1197-1210

- Moland E, Olsen EM, Knutsen H, Knutsen JA, Enersen SE, Andre C, Stenseth NC (2011b) Activity patterns of wild European lobster Homarus gammarus in coastal marine reserves: implications for future reserve design. Mar Ecol Prog Ser 429:197-207

> O'Grady DF, Jury SH, Watson WH III (2001) Use of a treadmill to study the relationship between walking, ventilation and heart rate in the lobster Homarus americanus. Mar Freshw Res 52:1387-1394

Patterson TA, Thomas L, Wilcox C, Ovaskainen O, Matthiopoulos J (2008) State-space models of individual animal movement. Trends Ecol Evol 23:87-94

Pawson MG (1995) Biogeographical identification of English Channel fish and shellfish stocks. Ministry of Agriculture, Fisheries and Food, Directorate of Fisheries Research, Lowestoft

Payne NL, Gillanders BM, Webber DM, Semmens JM (2010) Interpreting diel activity patterns from acoustic telemetry: the need for controls. Mar Ecol Prog Ser 419:295-301

Pezzack DS, Duggan R (1986) Evidence of migration and homing of lobsters (Homarus americanus) on the Scotian Shelf. Can J Fish Aquat Sci 43:2206-2211

Phillips BF (2013) Lobsters: biology, management, aquaculture and fisheries, 2nd edn. John Wiley \& Sons, Chichester

> Pittman SJ, McAlpine CA (2003) Movements of marine fish and decapod crustaceans: process, theory and application. Adv Mar Biol 44:205-294

> Pittman SJ, Christensen JD, Caldow C, Menza C, Monaco ME (2007) Predictive mapping of fish species richness across shallow-water seascapes in the Caribbean. Ecol Model 204:9-21

Rodgers AR, Carr AP (2001) HRE: the home range extension for ArcView ${ }^{\mathrm{TM}}$. Ontario Ministry of Natural Resources, Centre for Northern Forest Ecosystem Research, Thunder Bay

Rogers KB, White GC (2007) Analysis of movement and habitat use from telemetry data. In: Christopher SG, Brown ML (eds) Analysis and interpretation of freshwater fisheries data. American Fisheries Society, Bethesda, MD, p 625-676

> Rowe S (2001) Movement and harvesting mortality of American lobsters (Homarus americanus) tagged inside and outside no-take reserves in Bonavista Bay, Newfoundland. Can J Fish Aquat Sci 58:1336-1346

Scheel D, Bisson L (2012) Movement patterns of giant Pacific octopuses, Enteroctopus dofleini (Wülker, 1910). J Exp Mar Biol Ecol 416-417:21-31

Schippers P, Verboom J, Knaapen JP, van Apeldoorn RC (1996) Dispersal and habitat connectivity in complex heterogeneous landscapes: an analysis with a GIS-based random walk model. Ecography 19:97-106

Scopel DA, Golet WJ, Watson WH III (2009) Home range dynamics of the American lobster, Homarus americanus. Mar Freshw Behav Physiol 42:63-80

Seaman DE, Powell RA (1996) An evaluation of the accuracy 
of kernel density estimators for home range analysis. Ecology 77:2075-2085

Silverman BW (1986) Density estimation for statistics and data analysis, Vol 26. CRC press, Boca Raton, FL

Simpfendorfer CA, Heupel MR, Hueter RE (2002) Estimation of short-term centers of activity from an array of omnidirectional hydrophones and its use in studying animal movements. Can J Fish Aquat Sci 59:23-32

Simpson AC (1961) A contribution to the bionomics of the lobster Homarus vulgaris Edw. on the coast of North Wales. HM Stationery Office, London

Skajaa K, Fernö A, Løkkeborg S, Haugland EK (1998) Basic movement pattern and chemo-oriented search towards baited pots in edible crab (Cancer pagurus L.). Hydrobiologia 371/372:143-153

Smith F (2013) Understanding HPE in the VEMCO Positioning System (VPS). http://vemcocom/wp-content/uploads/ 2013/09/understanding-hpe-vps.pdf (accessed 18 Oct 2013)

Smith IP, Collins KJ, Jensen AC (1998) Movement and activity patterns of the European lobster, Homarus gammarus, revealed by electromagnetic telemetry. Mar Biol 132:611-623

Smith IP, Collins KJ, Jensen AC (1999) Seasonal changes in the level and diel pattern of activity in the European lobster Homarus gammarus. Mar Ecol Prog Ser 186:255-264

Smith IP, Collins KJ, Jensen AC (2000) Digital electromagnetic telemetry system for studying behaviour of decapod crustaceans. J Exp Mar Biol Ecol 247:209-222

Smith IP, Jensen AC, Collins KJ, Mattey EL (2001) Movement of wild European lobsters Homarus gammarus in natural habitat. Mar Ecol Prog Ser 222:177-186

Spanier E, McKenzie TP, Cobb JS, Clancy M (1998) Behavior of juvenile American lobsters, Homarus americanus, under predation risk. Mar Biol 130:397-406

Thomas HJ (1954) Observations on the recaptures of tagged lobsters in Scotland. ICES CM 1954(7). ICES, Copenhagen

Townsend CR, Dolédec S, Norris R, Peacock K, Arbuckle C (2003) The influence of scale and geography on relationships between stream community composition and landscape variables: description and prediction. Freshw Biol

Editorial responsibility: Romuald Lipcius,

Gloucester Point, Virginia, USA
48:768-785

Turchin P (1998) Quantitative analysis of movement: measuring and modeling population redistribution in animals and plants, Vol 1. Sinauer Associates, Sunderland, MA

$>$ van der Meeren GI (1997) Preliminary acoustic tracking of native and transplanted European lobsters (Homarus gammarus) in an open sea lagoon. Mar Freshw Res 48: 915-922

Walter WD, Fischer JW, Baruch-Mordo S, VerCauteren KC (2011) What is the proper method to delineate home range of an animal using today's advanced GPS telemetry systems: the initial step. In: Krejcar O (ed) Modern telemetry. InTech, Rijeka, p 249-268

Watson WH III, Vetrovs A, Howell WH (1999) Lobster movements in an estuary. Mar Biol 134:65-75

Watson WH III, Golet W, Scopel D, Jury S (2009) Use of ultrasonic telemetry to determine the area of bait influence and trapping area of American lobster, Homarus americanus, traps. N Z J Mar Freshw Res 43:411-418

> Wiens JA, Schooley RL, Weeks RD Jr (1997) Patchy landscapes and animal movements: Do beetles percolate? Oikos 78:257-264

- Wiig JR, Moland E, Haugen TO, Olsen EM, Jech JM (2013) Spatially structured interactions between lobsters and lobster fishers in a coastal habitat: fine-scale behaviour and survival estimated from acoustic telemetry. Can J Fish Aquat Sci 70:1468-1476

> Wiley EO, McNyset KM, Peterson AT, Robins CR, Stewart AM (2003) Niche modeling and geographic range predictions in the marine environment using a machinelearning algorithm. Oceanography (Wash DC) 16:120-127

- Wolf M, van Doorn GS, Leimar O, Weissing FJ (2007) Lifehistory trade-offs favour the evolution of animal personalities. Nature 447:581-584

> Worton BJ (1989) Kernel methods for estimating the utilization distribution in home-range studies. Ecology 70 : 164-168

- Worton BJ (1995) Using Monte Carlo simulation to evaluate kernel-based home range estimators. J Wildl Manag 59: 794-800

Zollner PA, Lima SL (1999) Search strategies for landscapelevel interpatch movements. Ecology 80:1019-1030

Submitted: January 29, 2015; Accepted: May 27, 2015

Proofs received from author(s): August 26, 2015 